\title{
MOF-Derived RuCo Catalyzes the Formation of Plasticizer Alcohol from Renewable Precursors
}

\author{
Constanze N. Neumann ${ }^{1}$, Steve Rozeveld ${ }^{2}$ and Mircea Dincă ${ }^{* 1}$ \\ ${ }^{1}$ Department of Chemistry, Massachusetts Institute of Technology, 77 Massachusetts Avenue, Cambridge, \\ Massachusetts 02139, United States. \\ ${ }^{2}$ Core R\&D, The Dow Chemical Company, Midland, Michigan 48674, United States. \\ *mdinca@mit.edu

\section{Contents}

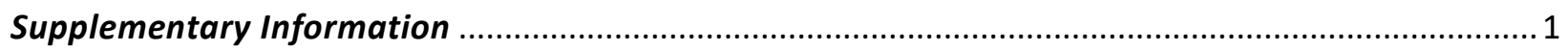

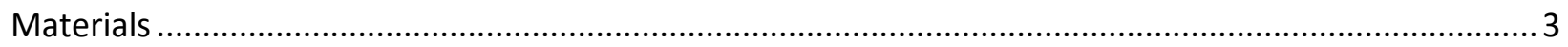

Synthesis of 1 .

Synthesis of 1 using $\mathrm{Ru}(\mathrm{nbd}) \mathrm{Cl}_{2}$ at elevated temperature (Method A) ......................................... 4

Synthesis of 1 using $\mathrm{Ru}(\mathrm{nbd}) \mathrm{Cl}_{2}$ at room temperature (Method B) ............................................. 4

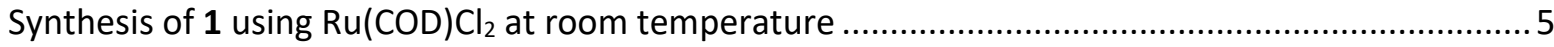

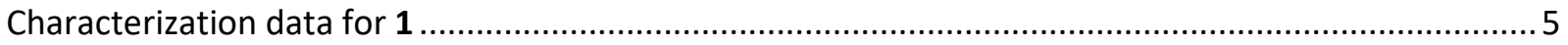

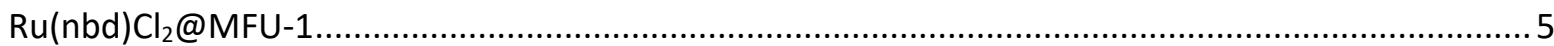

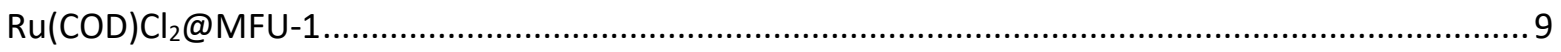

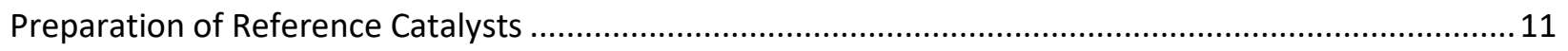

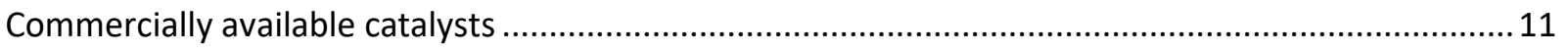

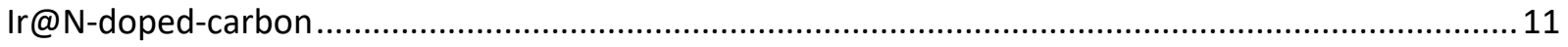

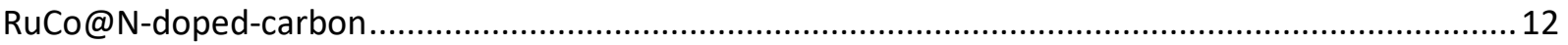

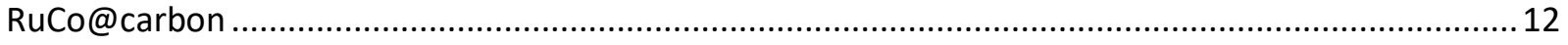

RuCo@carbon with a low loading ruthenium to cobalt ratio (RuCo@C-1) ........................................14

RuCo@carbon with a low loading ruthenium to cobalt ratio (RuCo@C-2) ........................................ 15

RuCo@carbon with low RuCo loading (RuCo@C-3) .......................................................................... 15

RuCo@carbon with high RuCo loading (RuCo@C-4) ............................................................................ 16

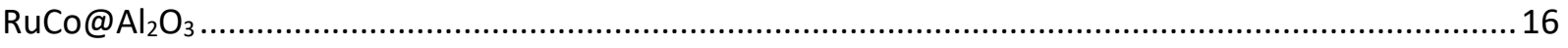

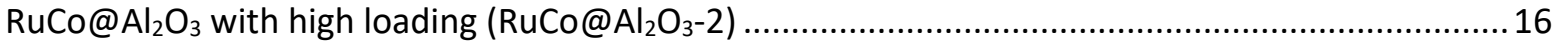




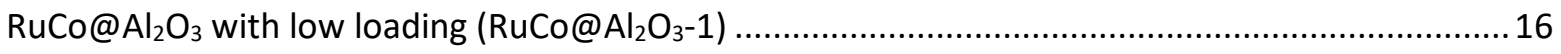

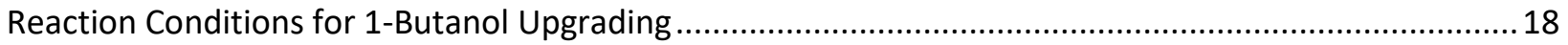

Preparation of $\mathrm{NaOBu}$ Solutions in 1-Butanol .............................................................................. 19

Calculation of reaction selectivity and turnover numbers ........................................................... 19

Calculation of the product selectivity and mass balance ............................................................. 19

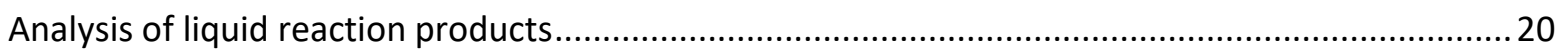

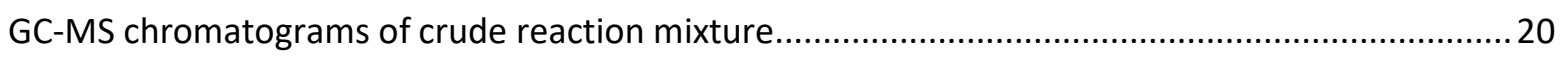

Experimental Procedure and Detailed Results for Experiments in Figure 3 ...................................... 20

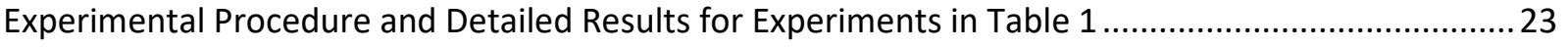

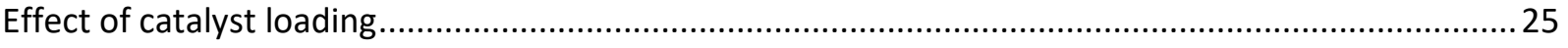

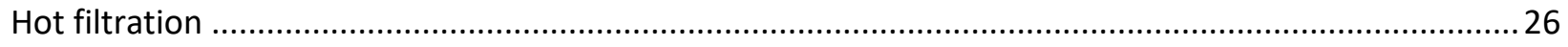

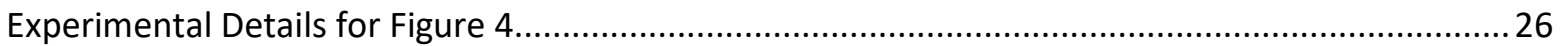

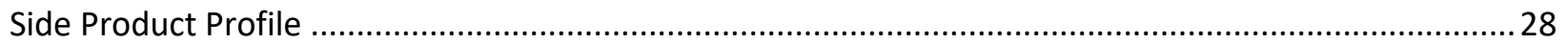

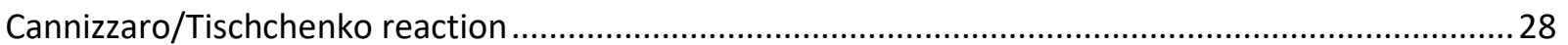

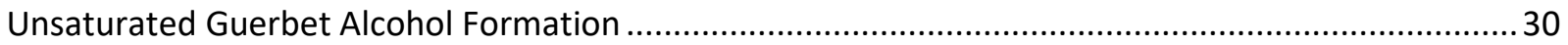

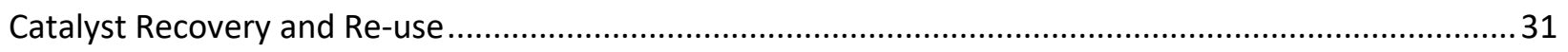

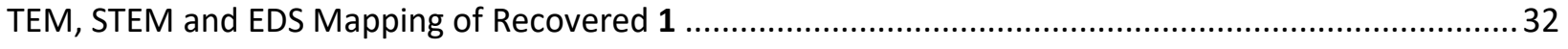

Ruthenium Enrichment on the Surface of CoOx nanoparticles ...................................................... 33

Effect of Nanoparticle Size and Composition on Catalyst Activity..................................................... 37

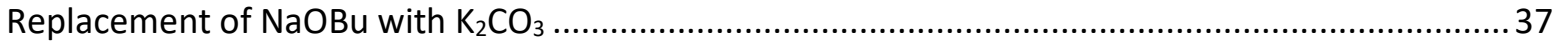

Experimental Procedure and Detailed Results for Experiments in Figure 6.....................................37

Butanol Upgrading with Base Promoters Other than NaOBu......................................................... 38

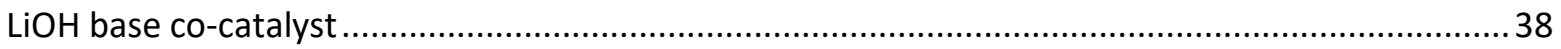

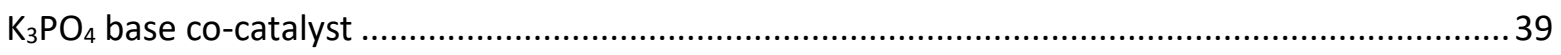

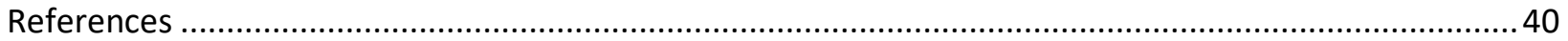




\section{Materials}

$\left[\mathrm{Ru}(\mathrm{COD}) \mathrm{Cl}_{2}\right]_{\mathrm{n}}, \mathrm{Co}\left(\mathrm{NO}_{3}\right)_{2} \cdot 6 \mathrm{H}_{2} \mathrm{O}$ and $\mathrm{m}$-xylene were purchased from Sigma-Aldrich and used as received. $\left[\mathrm{Ru}(\mathrm{nbd}) \mathrm{Cl}_{2}\right]_{\mathrm{n}}$ was purchased from Sigma-Aldrich or synthesized from $\mathrm{RuCl}_{3}$ according to a published procedure. ${ }^{1}$ MFU-1 for use in ruthenium incorporation reactions was synthesized according to a reported procedure. ${ }^{2}$

Powder X-ray diffraction (PXRD) patterns were recorded on a Bruker Advance II diffractometer equipped with $\theta / 2 \theta$ Bragg-Brentano geometry and Ni-filtered $\mathrm{Cu}-\mathrm{K} \alpha$ radiation $\left(K \alpha_{1}=1.5406 \AA\right)$. The tube voltage and current were $40 \mathrm{kV}$ and $40 \mathrm{~mA}$, respectively. Samples for PXRD were prepared by placing a thin layer of the appropriate material on a zero-background silicon crystal plate. Benchtop infrared (IR) spectra were recorded on a Bruker Tensor 37 instrument with a germanium attenuated total reflectance (ATR) sample holder. Nitrogen adsorption isotherms were performed using a Micromeritics ASAP 2020 Surface Area and Porosity Analyzer and UHP grade nitrogen (99.999\% purity).

Transition metal analysis was provided by inductively coupled plasma mass spectrometry (ICP-MS) on an Agilent 7900 at the MIT Center for Environmental Health Sciences (MIT CEHS). Calibration standards were prepared for ICP-MS analysis using analytical standard solutions purchased from Ricca Chemicals and $1 \% \mathrm{HNO}_{3}$ solution (prepared from EMD Millipore Omnitrace ${ }^{\odot} \mathrm{HNO}_{3}$ and ultrafiltered water). Sample digestion was performed using $\mathrm{H}_{2} \mathrm{SO}_{4}$ (OmniTrace Ultra ${ }^{\mathrm{TM}}$, EMD Millipore) or $\mathrm{HNO}_{3}$ (Omnitrace ${ }^{\odot}$, EMD). Thermal gravimetric (TGA) analyses were conducted using a TA Instruments Q500 analyzer equipped with a standard furnace (953032.901, TA Instruments) and a platinum pan (952018.906, TA Instruments). 5-10 mg of sample was subjected to an equilibration step at $30^{\circ} \mathrm{C}$ followed by a heat ramp to $700{ }^{\circ} \mathrm{C}$ at a rate of $1^{\circ} \mathrm{C} / \mathrm{min}$ under a constant flow of air or nitrogen $(5.0 \mathrm{~mL} / \mathrm{min})$.

Samples for TEM imaging were prepared by mixing a small amount of powder sample with isopropanol or methanol. The fines were collected onto a standard Cu mesh TEM grid with a lacy carbon support. Data collection was performed using a FEI Themis field emission gun (FEG) aberration-corrected (probe) transmission electron microscope (TEM). The TEM was operated at an accelerating voltage $200 \mathrm{keV}$. STEM images were collected at $2048 \times 2048$ image size. The Themis has Bruker AXS XFlash energy dispersive X-ray spectrometer (EDS) detectors with an energy resolution of $137 \mathrm{eV} /$ channel for elemental identification and quantitative analysis. Instrument conditions: STEM 55-100 pA 70 $\mathrm{mm}$ C2 Spot 9 for imaging, 300-500 pA for EDS map collection, 700-1500 second collection time per map, $1024 \times 1024$ map size.

For XPS analysis, samples were mounted using double sided copper tapes and spectra were collected using PHI VersaProbe II (X-ray source: monochromatic Al Ka, $200 \mu \mathrm{m}, 50 \mathrm{~W}, 15 \mathrm{kV}$ ). Quantification of elements was calculated using the integrated peak intensities under the indicated transition, corrected for the instrument-specific cross section (sensitivity factor) for a PHI VersaProbe II spectrometer. The elemental compositions were calculated assuming that the elements detected account for $100 \%$ of the species on the surface. The binding energy (BE) scale was calibrated to compensate for surface charging, by setting the graphitic $\mathrm{C} 1 \mathrm{~s}$ to $284.6 \mathrm{eV}$ and aliphatic $\mathrm{C}$ 1s to $285.0 \mathrm{eV}$. 


\section{Synthesis of 1}

The MOF support used for the preparation of $\mathbf{1}$ was synthesized according to a published procedure. ${ }^{2}$

Synthesis of 1 using Ru(nbd) $\mathrm{Cl}_{2}$ at elevated temperature (Method A)

$$
\begin{gathered}
\mathrm{Co}_{4} \mathrm{O}(3,5-\mathrm{dmpz})_{6} \\
(\mathrm{MFU}-1)
\end{gathered}
$$

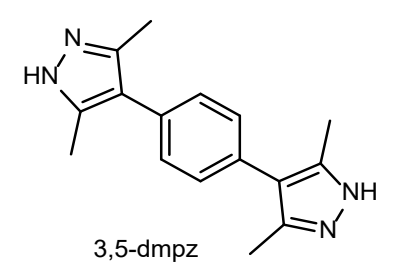

\author{
$\left[\mathrm{Ru}(\mathrm{nbd}) \mathrm{Cl}_{2}\right]_{\mathrm{n}}$ \\ $\mathrm{DMF}, 80^{\circ} \mathrm{C}, 3 \mathrm{~h}$ \\ $\mathrm{Ru}(\mathrm{nbd}) \mathrm{Cl} 2 @ \mathrm{MFU}-1$
}

Under air, MFU-1 (0.120 mmol, 220 mg, 1.00 equiv) and $\mathrm{Ru}(\mathrm{nbd}) \mathrm{Cl}_{2}$ (0.076 mmol, $20.0 \mathrm{mg}, 0.67$ equiv) were placed in a pyrex reaction vessel and DMF $(100 \mathrm{~mL})$ was added. The reaction mixture was left to stir at $80^{\circ} \mathrm{C}$ for $3 \mathrm{~h}$ before it was filtered over a medium frit to isolate crude 1 . Residual $\mathrm{Ru}(\mathrm{nbd}) \mathrm{Cl}_{2}$ was removed by washing with DMF $(3 \times 100 \mathrm{~mL})$ and with ethanol $(3 \times 100 \mathrm{~mL})$. After drying under air at room temperature, 1 was collected as a dark blue solid $(0.118 \mathrm{mmol}, 217 \mathrm{mg}, 98 \%$ yield). A Ru:Co ratio of $0.049: 1.000$ was determined by ICP-MS analysis, and the structural integrity of the MOF support was verified by PXRD (Figure S2). Neither in the filtrate of the reaction mixture nor in the solvent used to wash 1 could cobalt be detected by ICP-MS analysis.

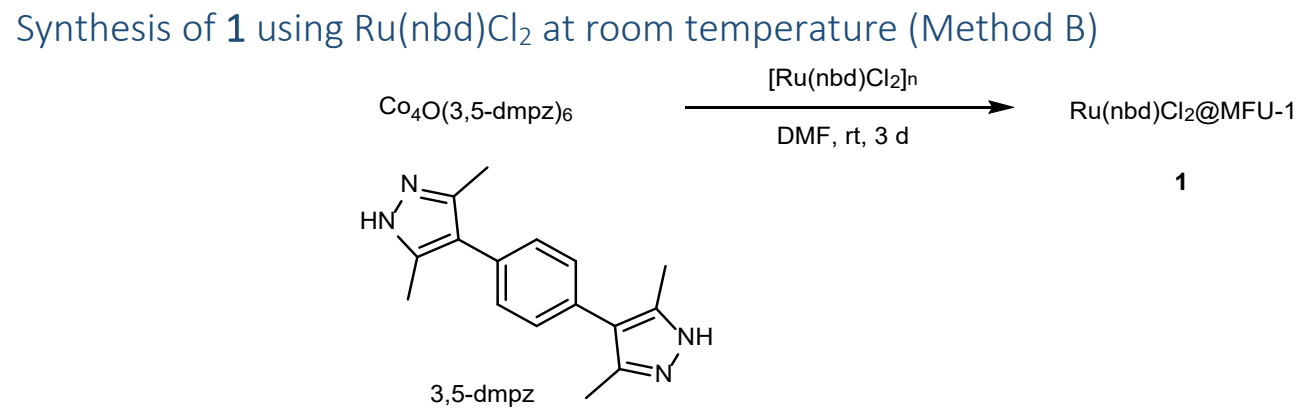

Under air, MFU-1 (74.0 $\mu \mathrm{mol}, 136 \mathrm{mg}, 1.00$ equiv) and $\mathrm{Ru}(\mathrm{nbd}) \mathrm{Cl}_{2}(71.0 \mu \mathrm{mol}, 20.0 \mathrm{mg}, 0.96$ equiv) were placed in a pyrex reaction vessel and DMF $(50 \mathrm{~mL})$ was added. The reaction mixture was left to stir at room temperature for $3 \mathrm{~d}$ and filtered over a medium frit to isolate crude 1 . Residual $\mathrm{Ru}(\mathrm{nbd}) \mathrm{Cl}_{2}$ was removed by washing with DMF $(3 \times 50 \mathrm{~mL})$ and with ethanol $(3 \times 50 \mathrm{~mL})$. After drying under air at room temperature, 1 was obtained as a dark blue solid $(65.0 \mu \mathrm{mol}, 120 \mathrm{mg}, 88 \%$ yield). A Ru:Co ratio of 0.018 : 1.000 was determined by ICP-MS analysis, and the structural integrity of the MOF support was verified by PXRD (Figure S2). 
Synthesis of 1 using $\mathrm{Ru}(\mathrm{COD}) \mathrm{Cl}_{2}$ at room temperature

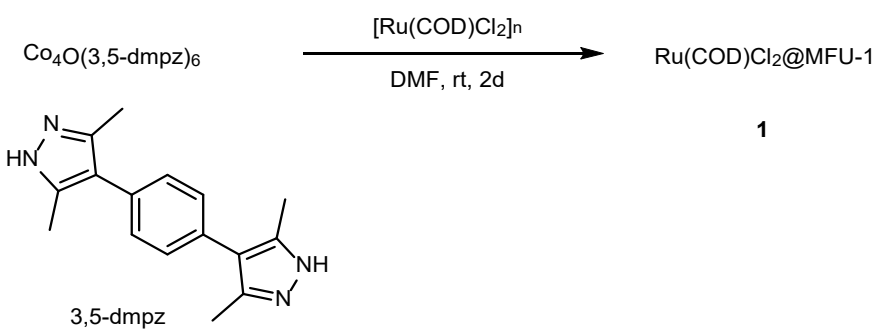

Under air, MFU-1 (0.127 mmol, $234 \mathrm{mg}, 1.00$ equiv) and $\mathrm{Ru}(\mathrm{COD}) \mathrm{Cl}_{2}(0.076 \mathrm{mmol}, 21.5 \mathrm{mg}, 0.67$ equiv) were placed in a pyrex reaction vessel and DMF $(18 \mathrm{~mL})$ was added. The reaction mixture was left to stir at room temperature for $2 \mathrm{~d}$ and filtered over a medium frit to isolate crude 1 . Residual $\mathrm{Ru}(\mathrm{COD}) \mathrm{Cl}_{2}$ was removed by washing with DMF $(3 \times 50 \mathrm{~mL})$ and with ethanol $(3 \times 50 \mathrm{~mL})$. After drying under air at room temperature, 1 was isolated as a dark blue solid $(0.125 \mathrm{mmol}, 230 \mathrm{mg}, 98 \%$ yield). A Ru:Co ratio of 0.010 $: 1.000$ was determined by ICP-MS to $\mathrm{Co}: \mathrm{Ru}=1.000: 0.010$, and the structural integrity of the MOF was verified by PXRD (Figure S8).

\section{Characterization data for 1}

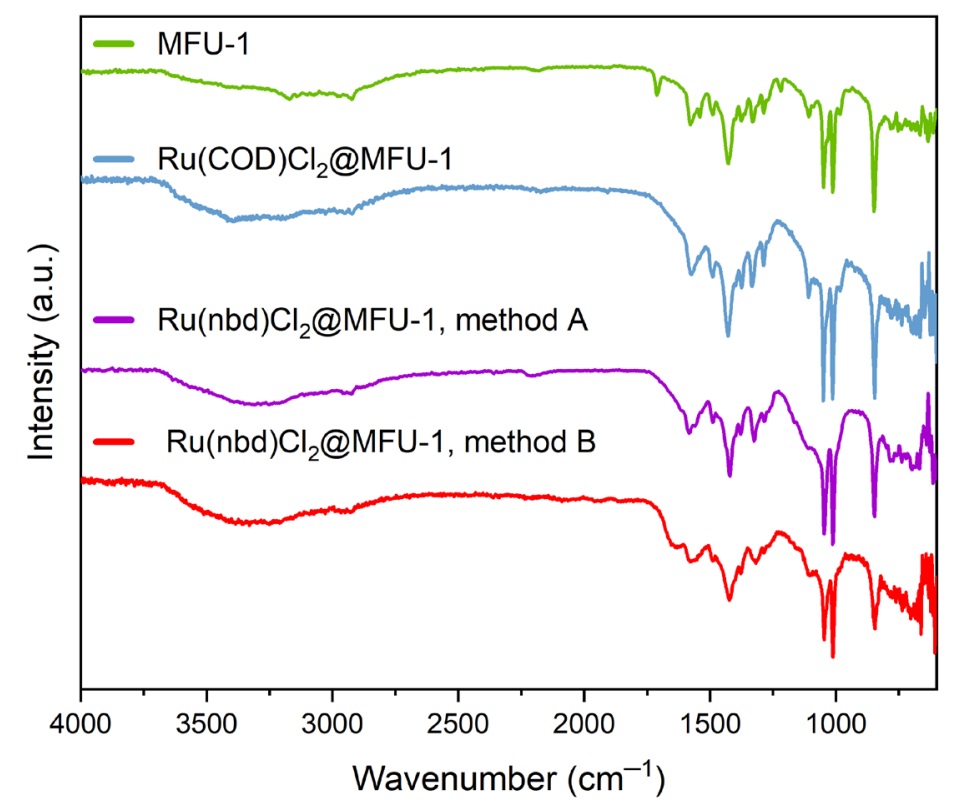

Figure S1. Comparison of infrared spectra of MFU-1 and batches of 1 prepared using different ruthenium precursors and synthesis conditions. 


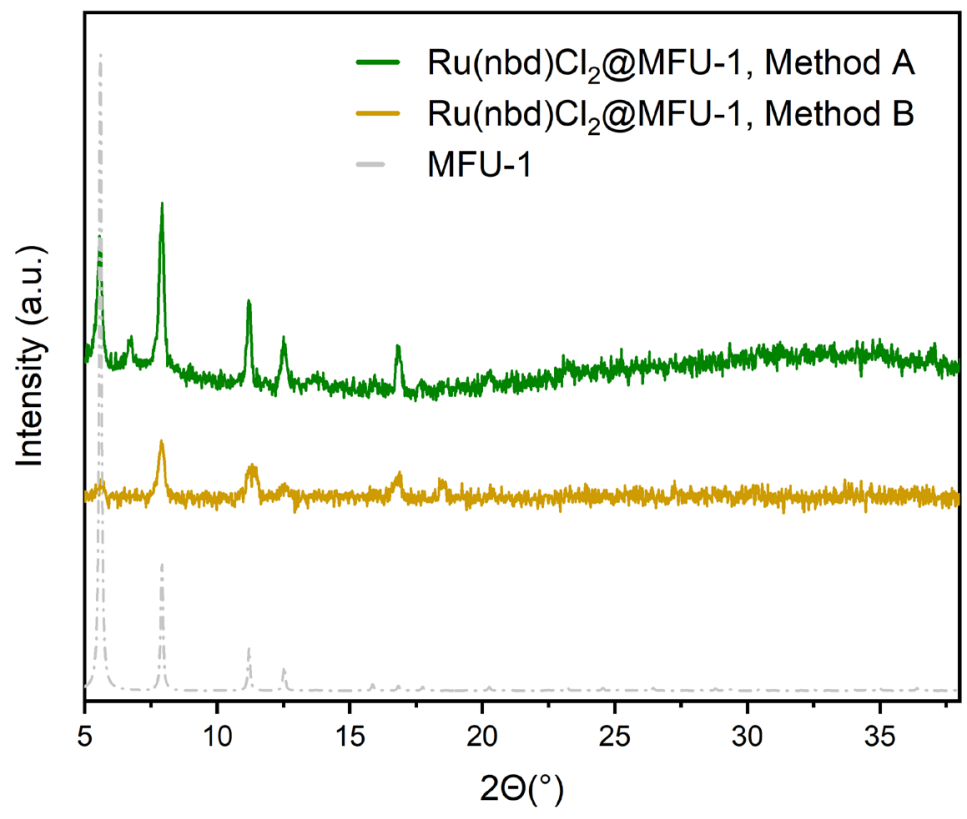

Figure S2. Comparison of the powder X-ray diffraction patterns of 1 prepared using $\mathrm{Ru}(\mathrm{nbd}) \mathrm{Cl}_{2}$ with the predicted pattern for MFU-1.

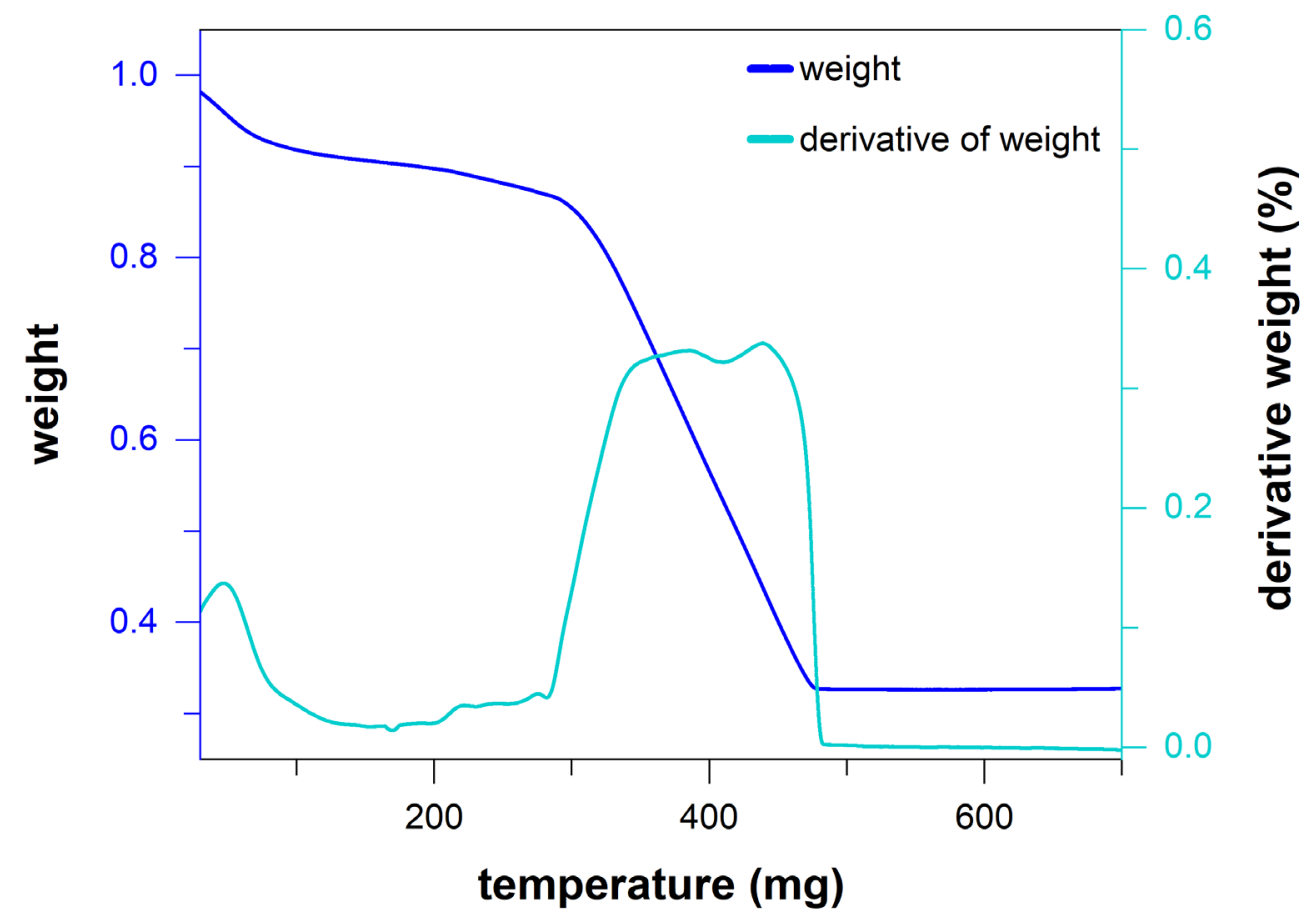

Figure S3. Thermogravimetric analysis of $1\left(\mathrm{Ru}(\mathrm{nbd}) \mathrm{Cl}_{2} @ \mathrm{MFU}-1, \mathrm{Co}: \mathrm{Ru}=1.000: 0.049\right)$ under nitrogen gas flow. 


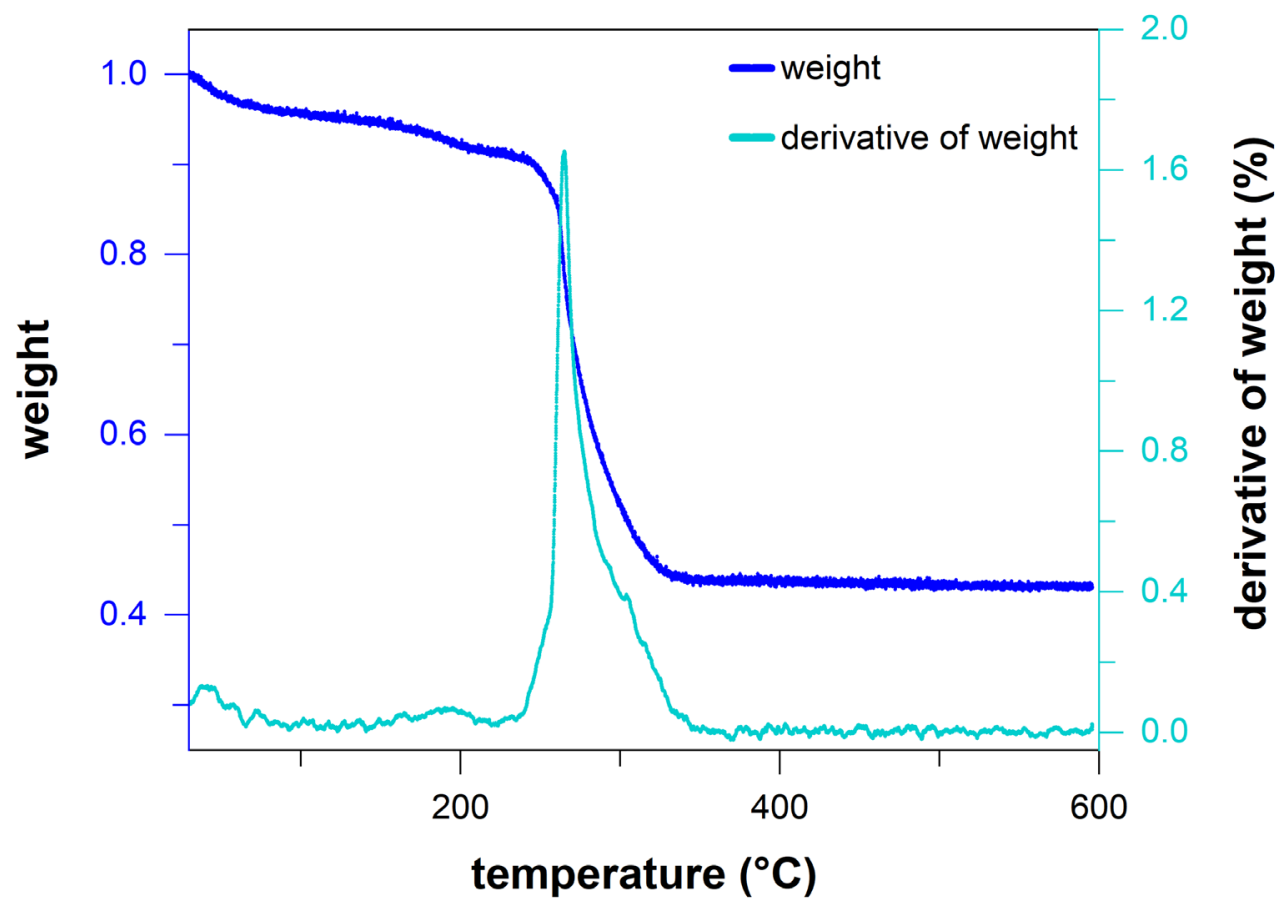

Figure S4. Thermogravimetric analysis of $1\left(\mathrm{Ru}(\mathrm{nbd}) \mathrm{Cl}_{2} @ \mathrm{MFU}-1, \mathrm{Co}: \mathrm{Ru}=1.000: 0.049\right)$ under air flow.

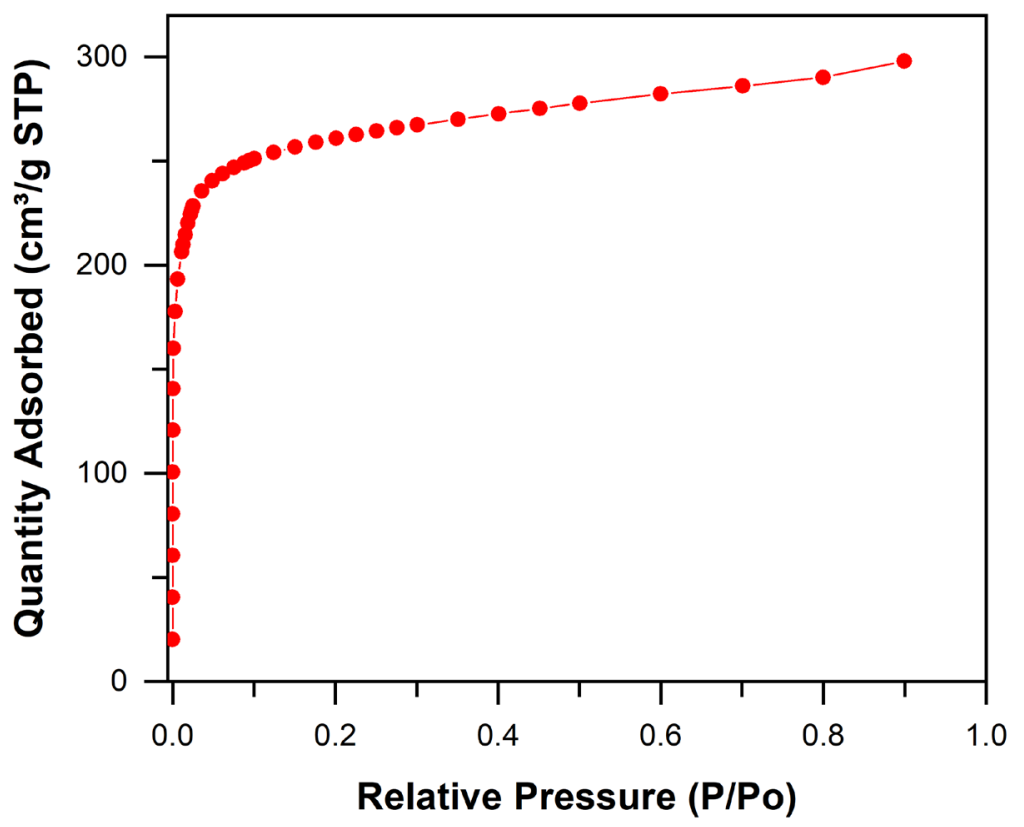

Figure S5. Nitrogen linear isotherm plot of $\mathbf{1}\left(\mathrm{Ru}(\mathrm{nbd}) \mathrm{Cl}_{2} @ \mathrm{MFU}-1\right.$, Method $\left.\mathrm{A}\right)$.

BET surface area: $1,034 \pm 6 \mathrm{~m}^{2} / \mathrm{g}$

Langmuir surface area: $1,051 \pm 12 \mathrm{~m}^{2} / \mathrm{g}$ 


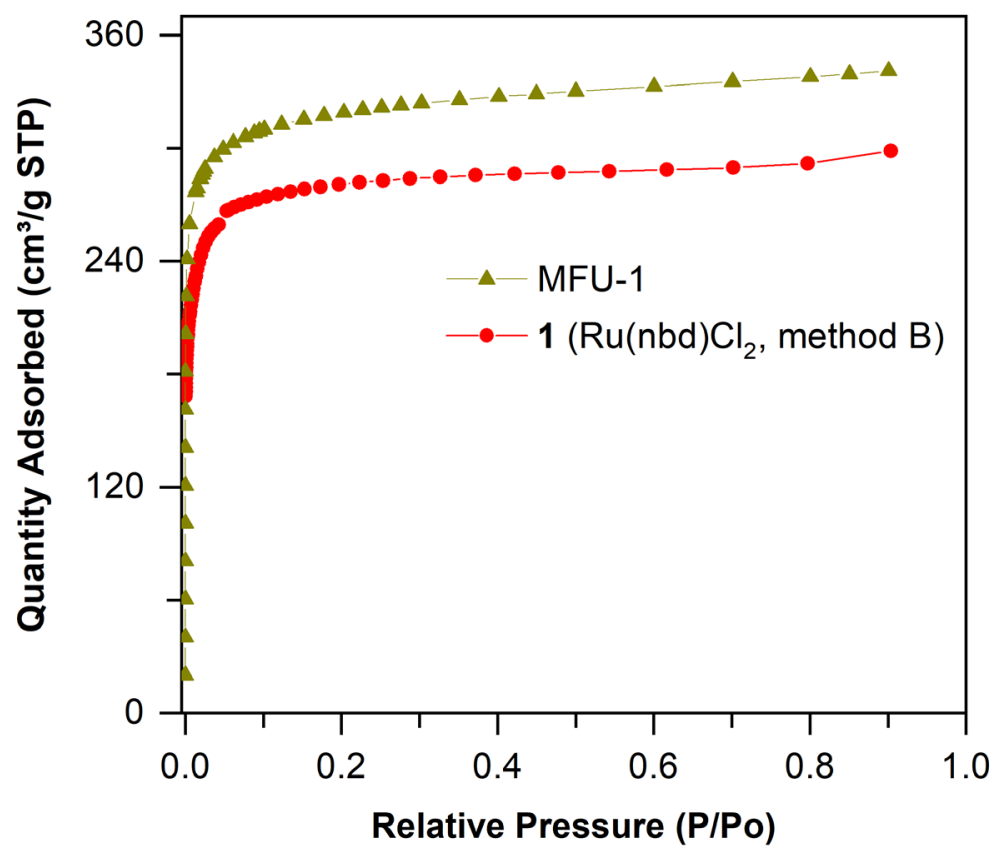

Figure S6. Nitrogen linear isotherm plot of $1\left(\mathrm{Ru}(\mathrm{nbd}) \mathrm{Cl}_{2} @ M F U-1\right.$, Method B).

BET surface area: $881 \pm 19 \mathrm{~m}^{2} / \mathrm{g}$

Langmuir surface area: $1,272 \pm 3 \mathrm{~m}^{2} / \mathrm{g}$

MFU-1 used to prepare 1:

BET surface area: $1,268 \pm 1 \mathrm{~m}^{2} / \mathrm{g}$

Langmuir surface area: 1,305 $\pm 8 \mathrm{~m}^{2} / \mathrm{g}$

(The BET surface area for MFU-1 obtained by microwave synthesis reported in the literature is $1485(50)$ $\left.\mathrm{m}^{2} / \mathrm{g}\right) \cdot{ }^{2-3}$ 


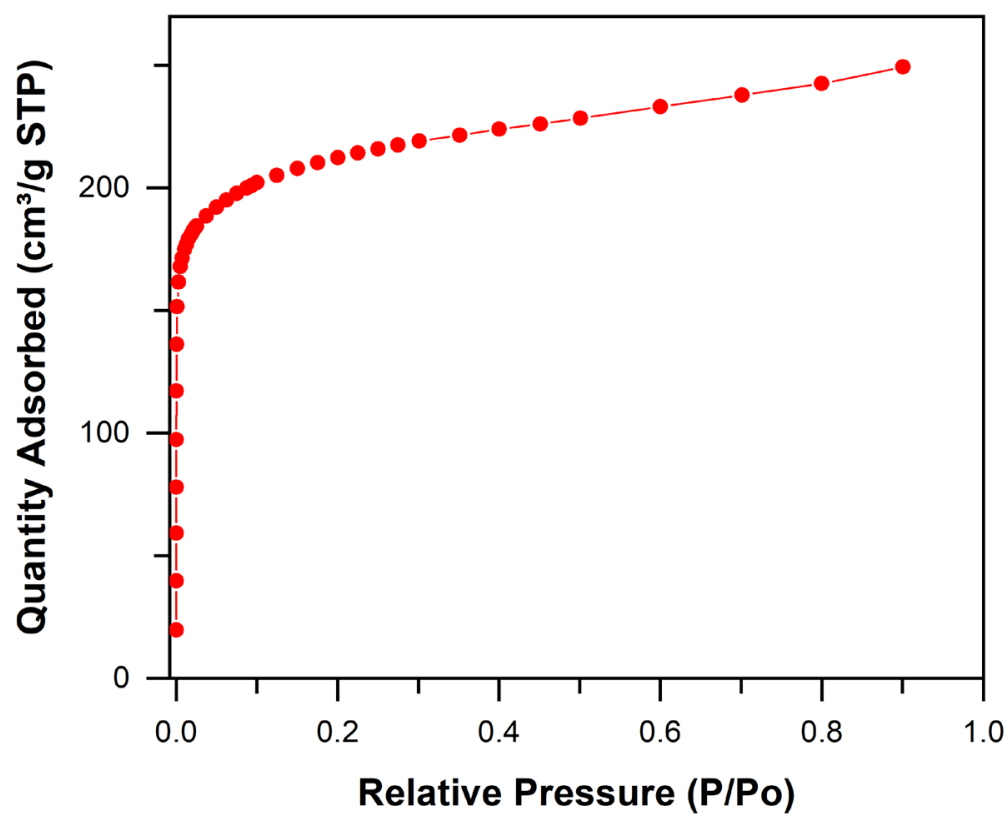

Figure S7. Nitrogen linear isotherm plot of $1\left(\mathrm{Ru}(\mathrm{COD}) \mathrm{Cl}_{2} @ M F U-1\right)$.

BET surface area: $804 \pm 1 \mathrm{~m}^{2} / \mathrm{g}$

Langmuir surface area: $840 \pm 6 \mathrm{~m}^{2} / \mathrm{g}$

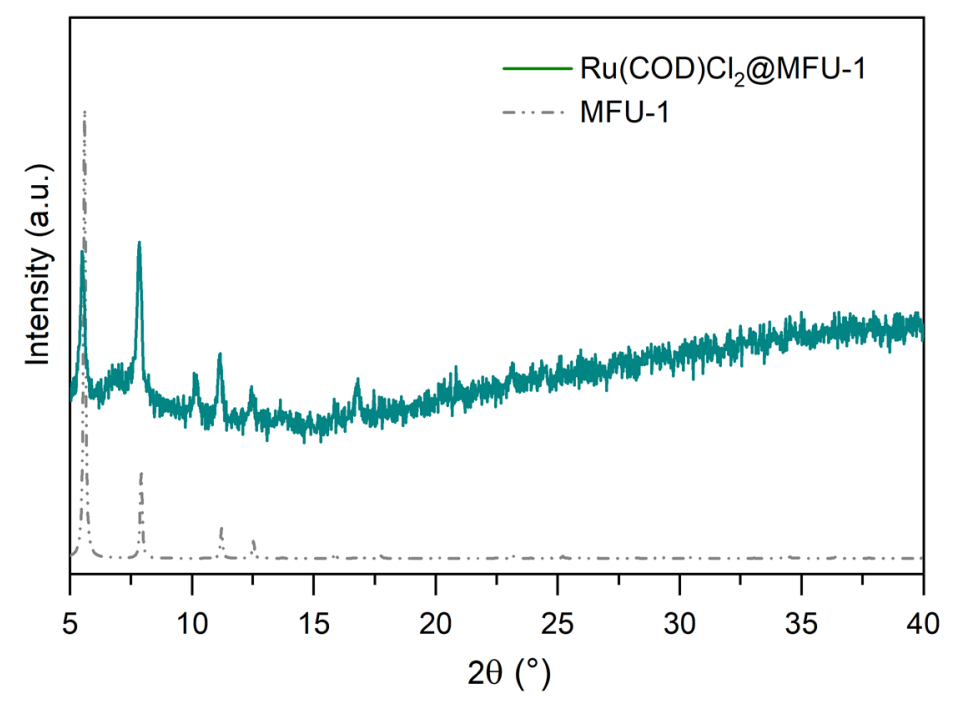

Figure S8. Comparison of the powder X-ray diffraction patterns of 1 prepared using $\mathrm{Ru}(\mathrm{COD}) \mathrm{Cl}_{2}$ and the predicted pattern for MFU-1. 


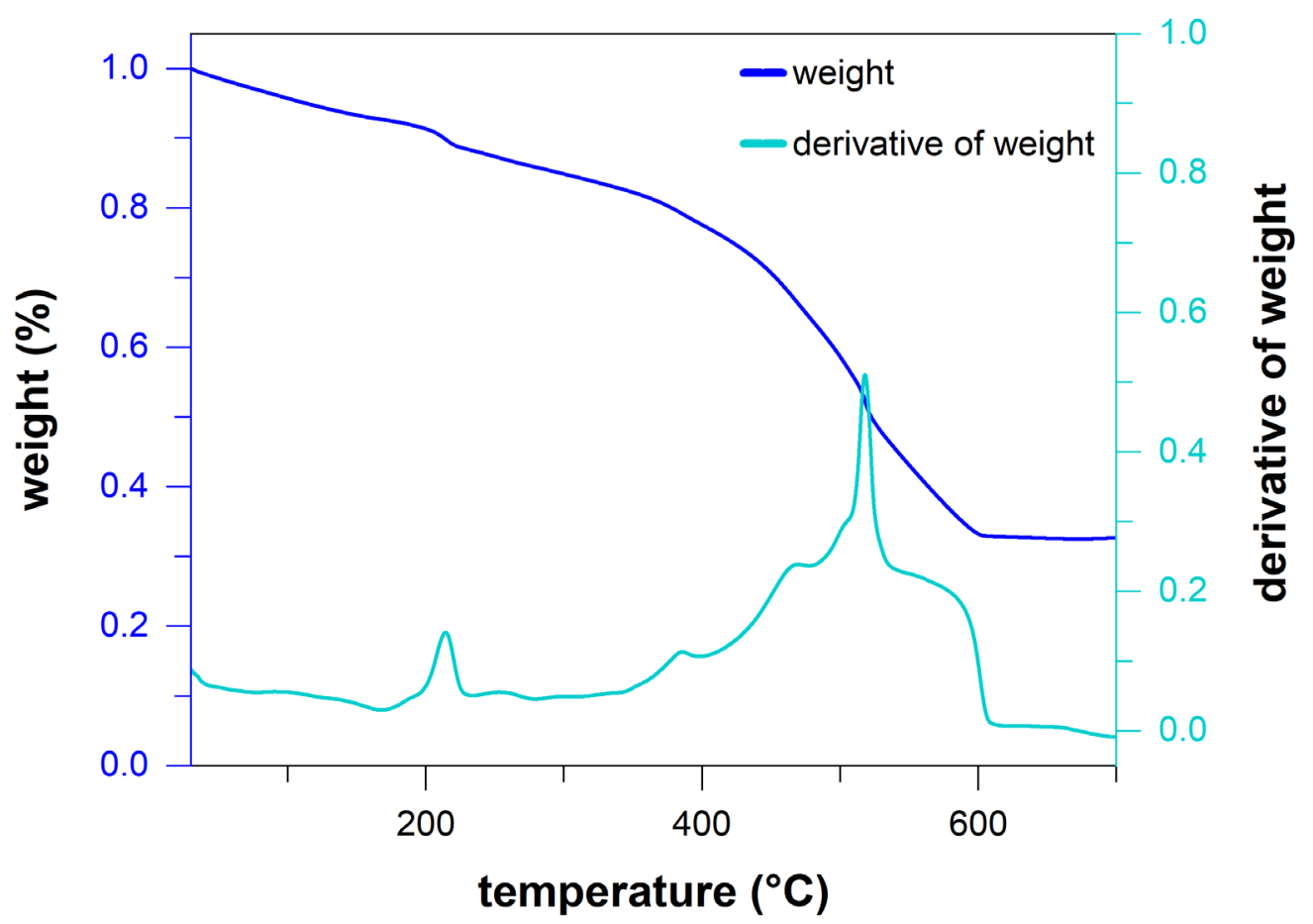

Figure S9. Thermogravimetric analysis of $1\left(\mathrm{Ru}(\mathrm{COD}) \mathrm{Cl}_{2} @ \mathrm{MFU}-1, \mathrm{Co}: \mathrm{Ru}=1.000: 0.018\right)$ under nitrogen gas flow.

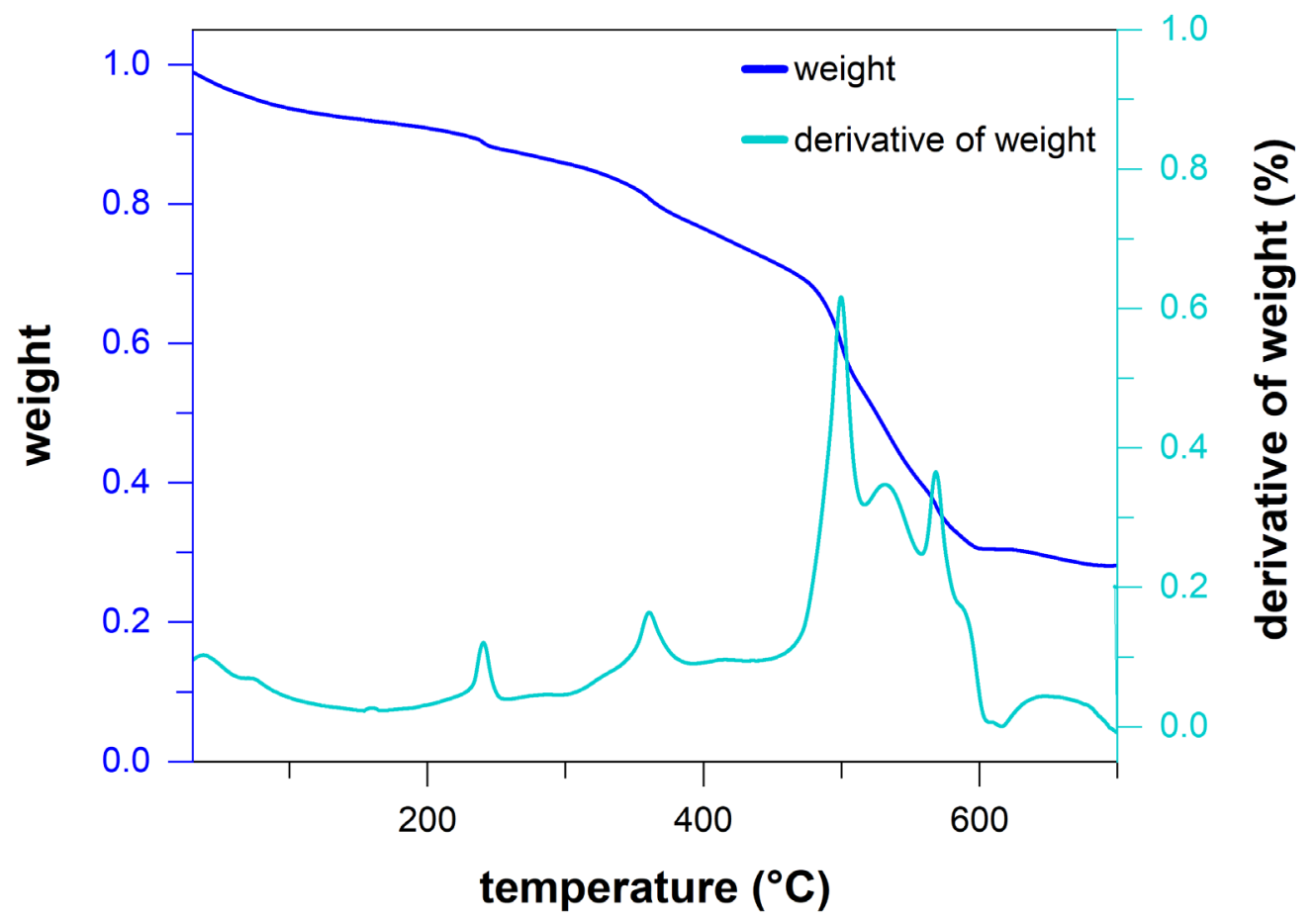

Figure S10. Thermogravimetric analysis of 1 (Ru(COD)Cl $@ M F U-1, C o: R u=1.000: 0.010)$ under nitrogen gas flow. 


\section{Preparation of Reference Catalysts}

\section{Commercially available catalysts}

The majority of catalysts subjected to butanol upgrading to benchmark the catalytic activity of RuCo catalysts (see Figure 3) were obtained from commercial sources (Table S1). Phenanthroline (phen) and bis(diphenylphosphino)methane (dppm) were purchased from Sigma-Aldrich.

\begin{tabular}{|c|c|c|c|}
\hline Catalyst & Supplier & Loading & Specifications \\
\hline Pd@C & Sigma-Aldrich & $10 w t \%$ & matrix carbon, dry support \\
\hline Rh@C & Strem & $5 w t \%$ & powder \\
\hline Ru@C & Strem & 5 wt\% & powder \\
\hline $\mathrm{Pt@Al}{ }_{2} \mathrm{O}_{3}$ & Spectrum Chemicals & 5 wt $\%$ & reduced, dry, $70 \mu \mathrm{m}$, BASF Catalyst \\
\hline $\mathrm{Ru}\left(\mathrm{PPh}_{3}\right)_{3} \mathrm{Cl}_{2}$ & Strem & NA & \\
\hline $\mathrm{IrCl}_{3} \cdot \mathrm{xH}_{2} \mathrm{O}$ & Strem & NA & \\
\hline$[\operatorname{Ir}(C O D) C I]_{2}$ & Strem & NA & \\
\hline$\left[\mathrm{Rh}(\mathrm{COE})_{2} \mathrm{Cl}\right]_{2}$ & Strem & NA & \\
\hline
\end{tabular}

Table S1. Suppliers, loadings and characteristics of commercial catalysts used.

\section{Ir@N-doped-carbon}

Ir@N-doped-carbon was prepared according to a published procedure and the characterization data obtained matched the reported material. ${ }^{4}$ The particular experimental procedure followed was for the material described in the original publication as $1 \% \mid \mathrm{I}-0.4 \mathrm{DMC}-550$, since it yielded the highest turnover frequency for the Guerbet reaction of 1-butanol. ${ }^{4}$ The use of $1 \mathrm{wt} \% \mathrm{IrCl}_{3}$ with relation to the support material gave rise to Ir@N-doped-C with an iridium loading of 0.55 wt\% as determined by ICP-MS (Figure S11). Assuming that no iridium is lost during calcination, the theoretical iridium loading on the support material was calculated to be $0.65 \mathrm{wt} \%$.

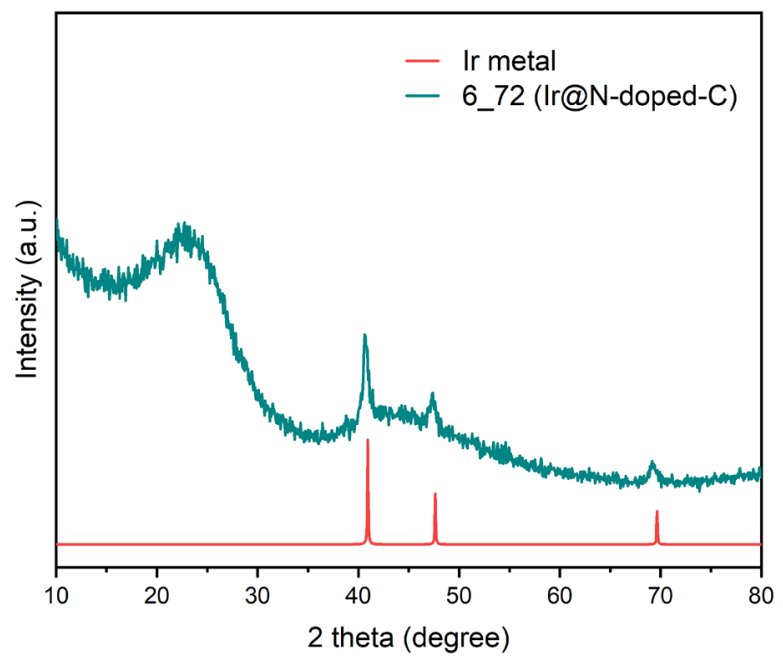


Figure S11. Powder X-ray diffraction pattern of Ir@N-doped-carbon used in butanol upgrading (see Table S3-S4 and Figure 3).

\section{RuCo@N-doped-carbon}

RuCo@N-doped-carbon was prepared analogously to Ir@N-doped-carbon using 0.4DMC-5504 (400 mg), $\mathrm{RuCl}_{3}(2.8 \mathrm{mg}, 0.013 \mathrm{mmol})$ and $\mathrm{CoCl}_{2}(77.4 \mathrm{mg}, 0.596 \mathrm{mmol})$ (Figure S12). The loading of ruthenium on the nitrogen-doped-carbon support was determined by inductively coupled plasma mass spectrometry (ICP-MS) to be $0.36 \mathrm{wt} \%$ (theoretical value, calculated assuming no loss of ruthenium during calcination: $0.34 \mathrm{wt} \%)$.

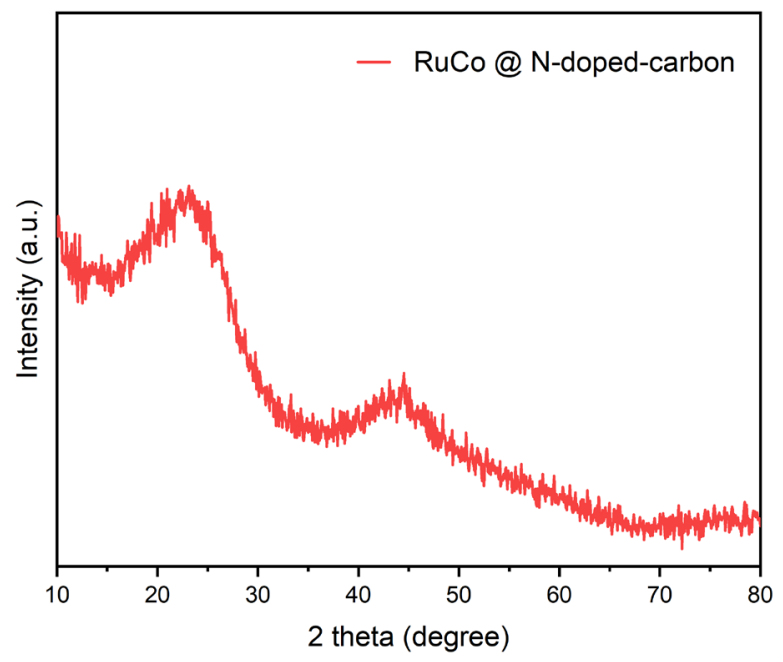

Figure S12. Powder X-ray diffraction pattern of RuCo@N-doped-carbon used in butanol upgrading (see Tables S3-S4 and Figure 3).

\section{RuCo@carbon}

RuCo@carbon catalysts containing different loadings of the alloy nanoparticles on the support as well as different $\mathrm{Ru}$ : Co ratios were prepared according to a literature procedure. ${ }^{5}$

For $150 \mathrm{mg}$ carbon black that has been activated by oxidation with $\mathrm{HNO}_{3},{ }^{5}$ the amounts of $\mathrm{RuCl}_{3}$ and $\mathrm{CoCl}_{2}$ listed in Table S2 were used to prepare the respective RuCo@C sample (Figure S13). The loading of ruthenium on the support material and the Ru : Co ratio was determined using ICP-MS. See Figures S35, S34 and S33 for XPS data for RuCo@C-1, RuCo@C-3 and RuCo@C-4, respectively.

\begin{tabular}{|c|c|c|c|c|c|c|}
\hline Sample ID & $\begin{array}{l}\mathrm{RuCl}_{3} \\
{[\mathrm{mg}]}\end{array}$ & $\begin{array}{l}\mathrm{CoCl}_{2} \\
{[\mathrm{mg}]}\end{array}$ & $\begin{array}{c}\text { Ru loading } \\
\text { [wt\%] }\end{array}$ & Ru : Co ratio & Calcination & Catalytic activity \\
\hline RuCo@C-1 & $10 \mathrm{mg}$ & $90 \mathrm{mg}$ & 0.7 & $0.011: 1$ & $200^{\circ} \mathrm{C}, 12 \mathrm{~h}$ & Table S10 \\
\hline RuCo@C-2 & $10 \mathrm{mg}$ & $90 \mathrm{mg}$ & 0.7 & $0.011: 1$ & $500{ }^{\circ} \mathrm{C}, 6 \mathrm{~h}$ & Table S10 \\
\hline RuCo@C-3 & $18 \mathrm{mg}$ & $45 \mathrm{mg}$ & 1.1 & $0.127: 1$ & $200^{\circ} \mathrm{C}, 12 \mathrm{~h}$ & Table S10, Figure 3 \\
\hline RuCo@C-4 & $36 \mathrm{mg}$ & $90 \mathrm{mg}$ & 3.4 & $0.116: 1$ & $200^{\circ} \mathrm{C}, 12 \mathrm{~h}$ & Figure 3 \\
\hline
\end{tabular}

Table S2. Preparation conditions and loading for RuCo@C samples. 
Half of the material from RuCo@C-1, for which STEM analysis indicated that $5 \mathrm{~nm}$ nanoparticles were evenly distributed on the support material (Figure S14), was subjected to calcination under reducing conditions $\left(5 \% \mathrm{H}_{2}\right.$ in $\mathrm{N}_{2}$ ) to yield RuCo@C-2, for which STEM analysis showed a less homogeneous particle size distribution and an overall increase in particle size (Figure S15). For both RuCo@C-3 and RuCo@C-4, $\mathrm{CoO}_{x}$ nanoparticles ranging in size between $5 \mathrm{~nm}$ and $10 \mathrm{~nm}$ were formed (Figure S16 and $\mathrm{S} 17$, respectively). Elemental mapping indicated that ruthenium and cobalt were co-located throughout the samples (Figure S14-S17).

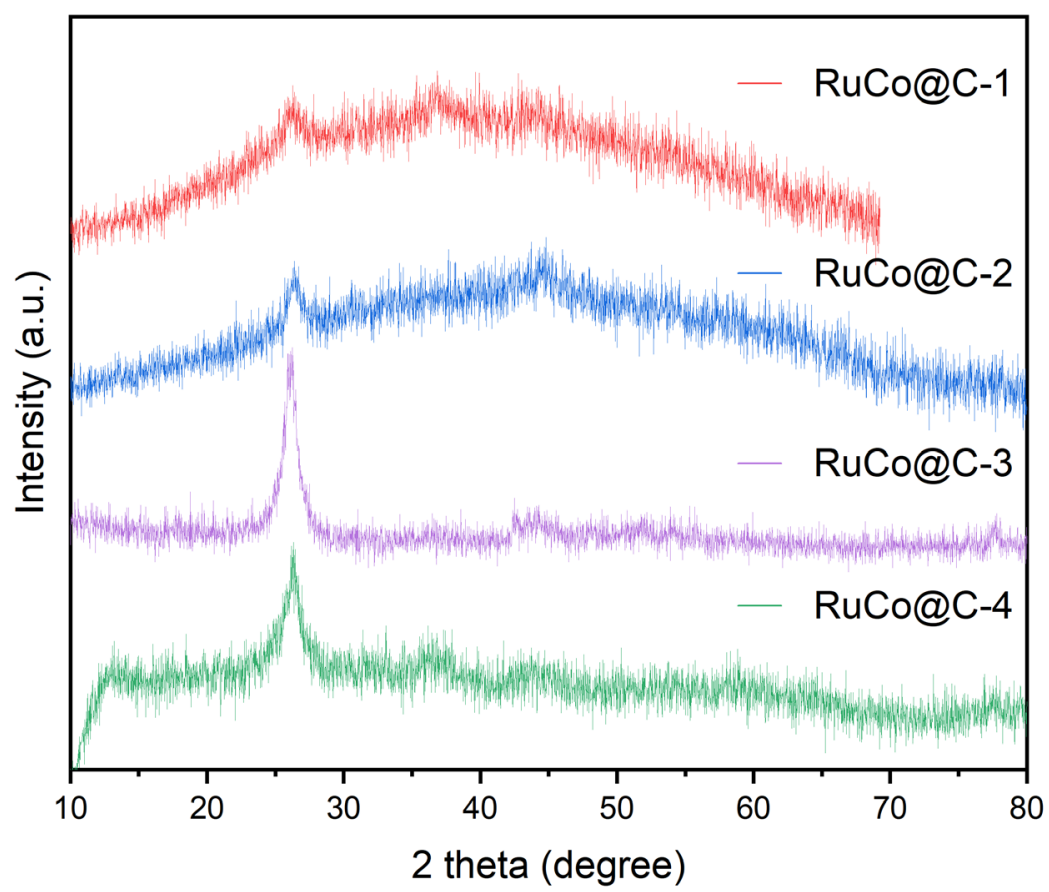

Figure S13. Powder X-ray diffraction patterns of RuCo@C samples. 
RuCo@carbon with a low loading ruthenium to cobalt ratio (RuCo@C-1)

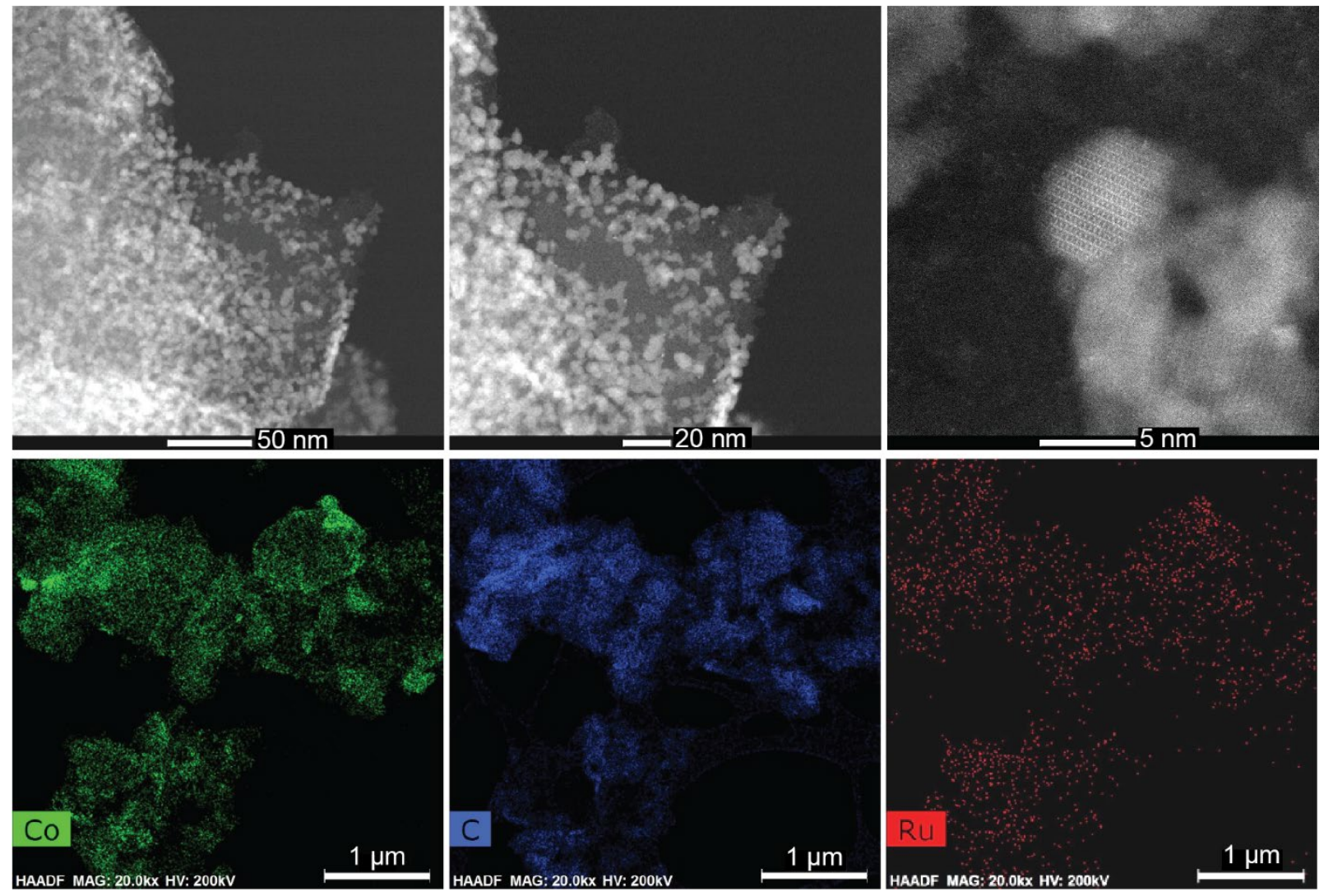

Figure S14. STEM images and EDS mapping of RuCo@C-1. 
RuCo@carbon with a low loading ruthenium to cobalt ratio (RuCo@C-2)
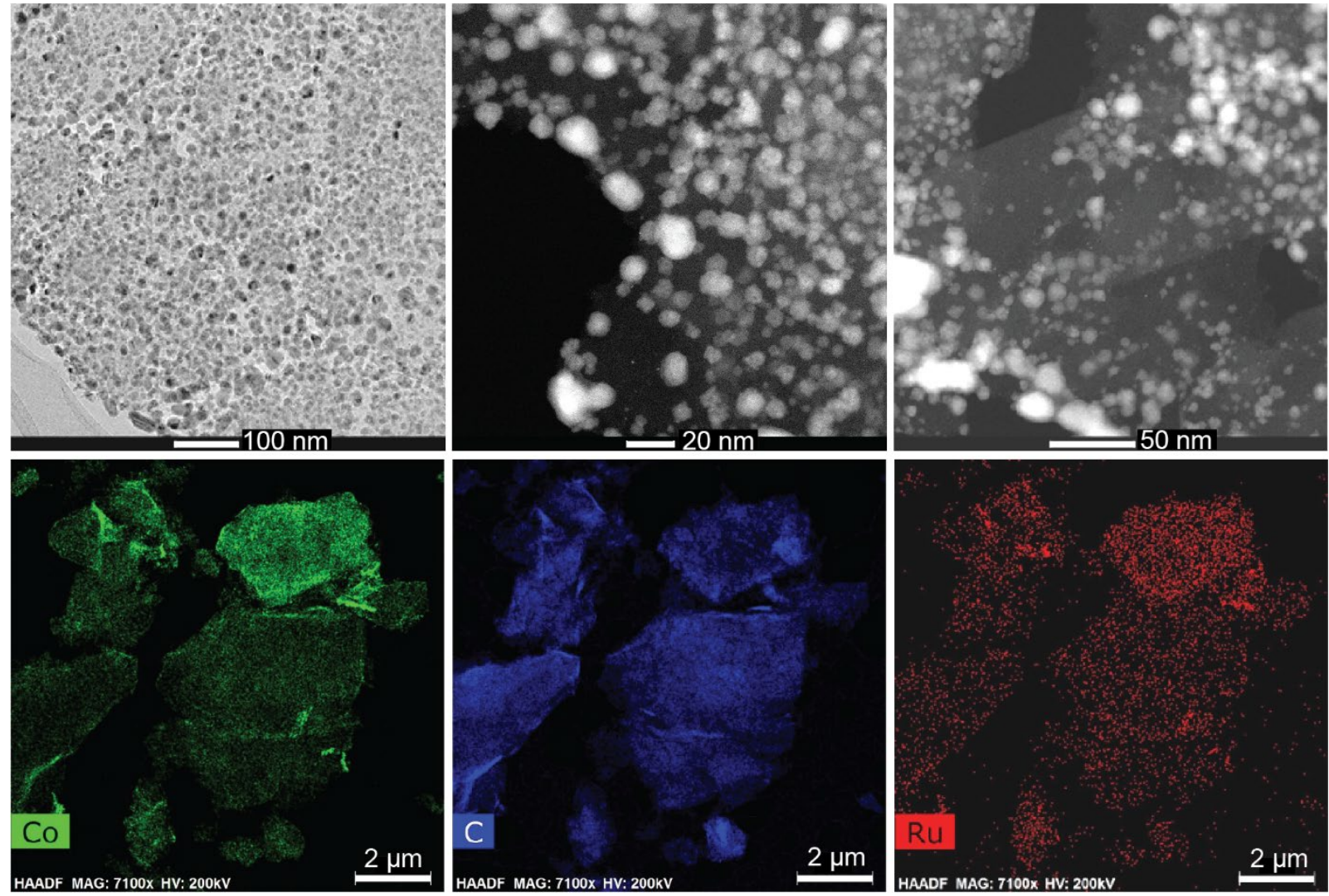

Figure S15. TEM image, STEM images and EDS mapping of RuCo@C-2.

RuCo@carbon with low RuCo loading (RuCo@C-3)
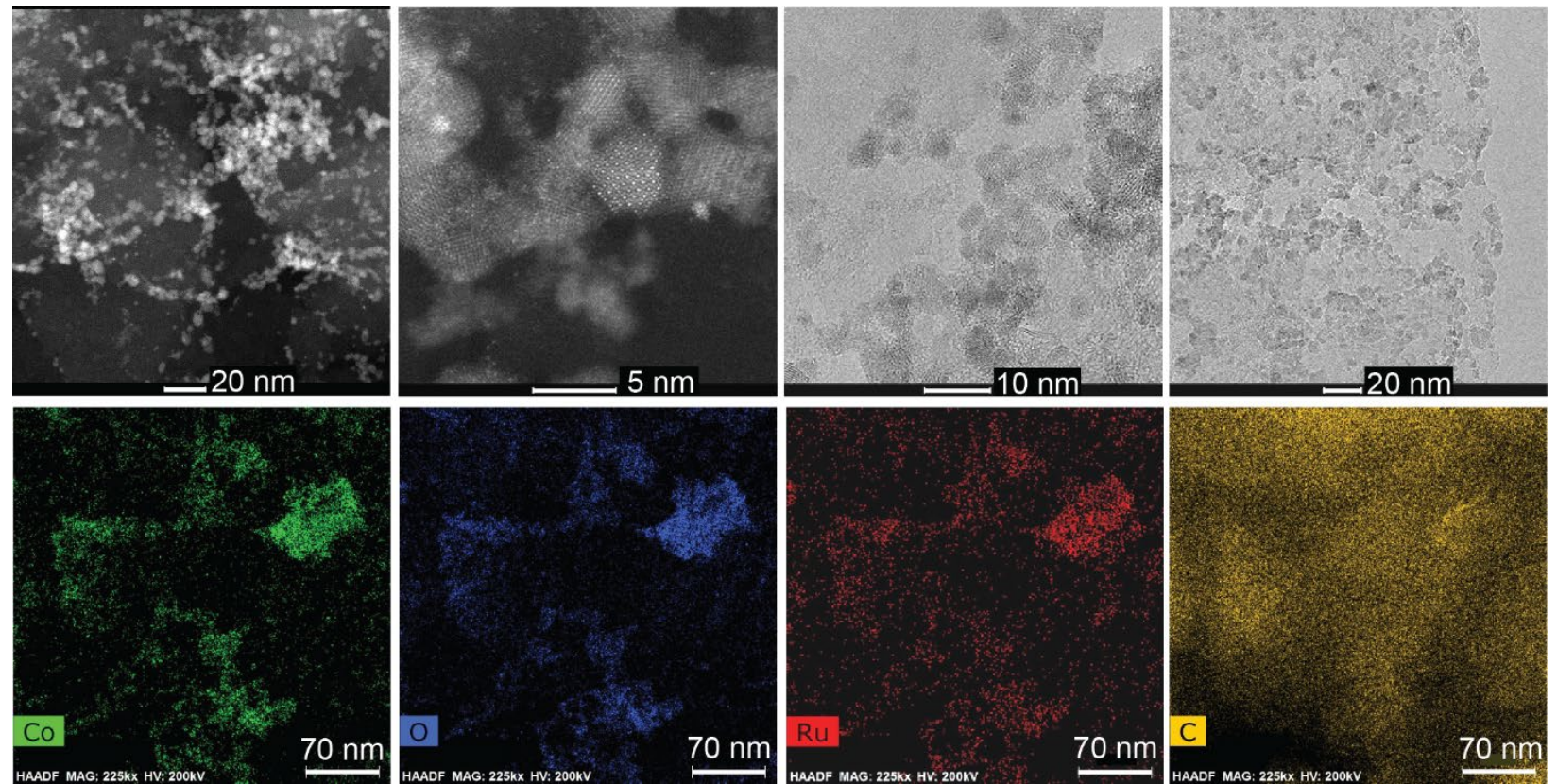

$10 \mathrm{n}$

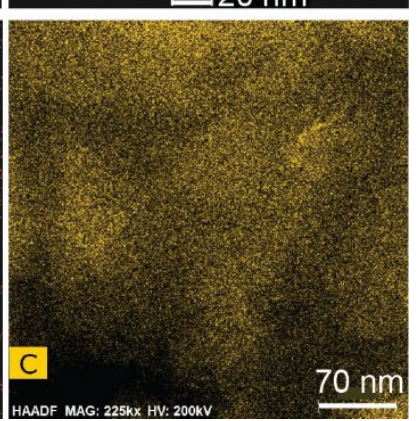

Figure S16. STEM images, TEM images and EDS mapping of RuCo@C-3. 

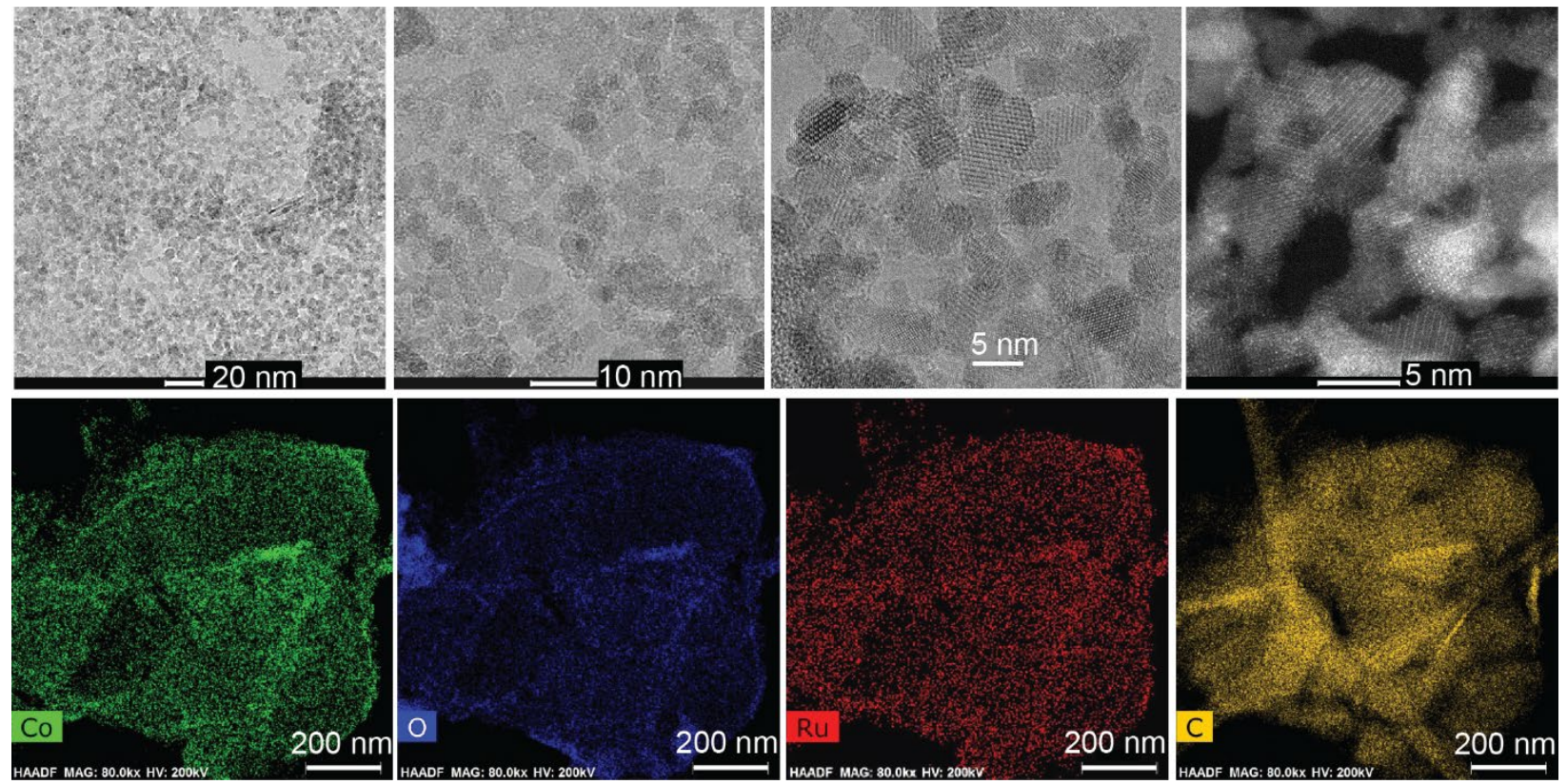

Figure S17. STEM images, TEM images and EDS mapping of RuCo@C-4.

\section{RuCo@ $\mathrm{Al}_{2} \mathrm{O}_{3}$}

\section{RuCo@ $\mathrm{Al}_{2} \mathrm{O}_{3}$ with high loading (RuCo@ $\mathrm{Al}_{2} \mathrm{O}_{3}-2$ )}

RuCo@ $\mathrm{Al}_{2} \mathrm{O}_{3}$ was synthesized according to a modified literature procedure. ${ }^{6}$ In a two-necked round bottom flask, $\mathrm{Ru}(\mathrm{acac})_{3}$ (acac = acetylacetonate, $13.5 \mathrm{mg}, 0.034 \mathrm{mmol}, 3.4 \cdot 10^{-3}$ equiv) and $\mathrm{Co}(\mathrm{acac})_{3}(120$ $\mathrm{mg}, 0.34 \mathrm{mmol}, 0.034$ equiv) were dissolved in ethylene glycol $(50.0 \mathrm{~mL})$. The flask was evacuated under oil pump vacuum ( $2 \mathrm{~min}$ ) without cooling and stirred at $185^{\circ} \mathrm{C}$ for $3 \mathrm{~h}$. The resulting black slurry was cooled to $100{ }^{\circ} \mathrm{C}$ and $\gamma-\mathrm{Al}_{2} \mathrm{O}_{3}(1.00 \mathrm{~g}, 9.81 \mathrm{mmol}, 1.00$ equiv) was added under nitrogen flow in one portion. After $12 \mathrm{~h}$, the slurry was cooled to room temperature. The black precipitate was isolated by filtration, washed with ethanol $(3 \times 20 \mathrm{~mL})$, and under reduced pressure at $60^{\circ} \mathrm{C}$ for $12 \mathrm{~h}$ to give $121 \mathrm{mg}$ of RuCo@ $\mathrm{Al}_{2} \mathrm{O}_{3}$ with a high loading of RuCo $\left(\mathrm{RuCo} @ \mathrm{Al}_{2} \mathrm{O}_{3}-2\right)$ as a dark gray powder. By ICP-MS analysis, the $\mathrm{Ru}$ : Co ratio of RuCo@ $\mathrm{Al}_{2} \mathrm{O}_{3}-2$ was determined to be $0.132: 1.000$, and the Ru content of the material was found to be 1.8 wt\%. For XPS data for RuCo@ $@ \mathrm{Al}_{2} \mathrm{O}_{3}-2$ see Figure S36.

\section{RuCo@ $\mathrm{Al}_{2} \mathrm{O}_{3}$ with low loading (RuCo@ $\mathrm{Al}_{2} \mathrm{O}_{3}-1$ )}

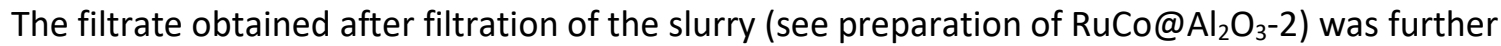
subjected to centrifugation and the solid collected was washed with ethanol $(3 \times 20 \mathrm{~mL})$ to yield $58 \mathrm{mg}$ of RuCo@Al $\mathrm{O}_{3}$ containing a low loading of RuCo (RuCo@ $\left.\mathrm{Al}_{2} \mathrm{O}_{3}-1\right)$ as a light gray powder. By ICP-MS analysis, the Ru : Co ratio of RuCo@ $\mathrm{Al}_{2} \mathrm{O}_{3}-1$ was determined to be $0.077: 1.000$, and the Ru content of the material was found to be $0.2 \mathrm{wt} \%$. 

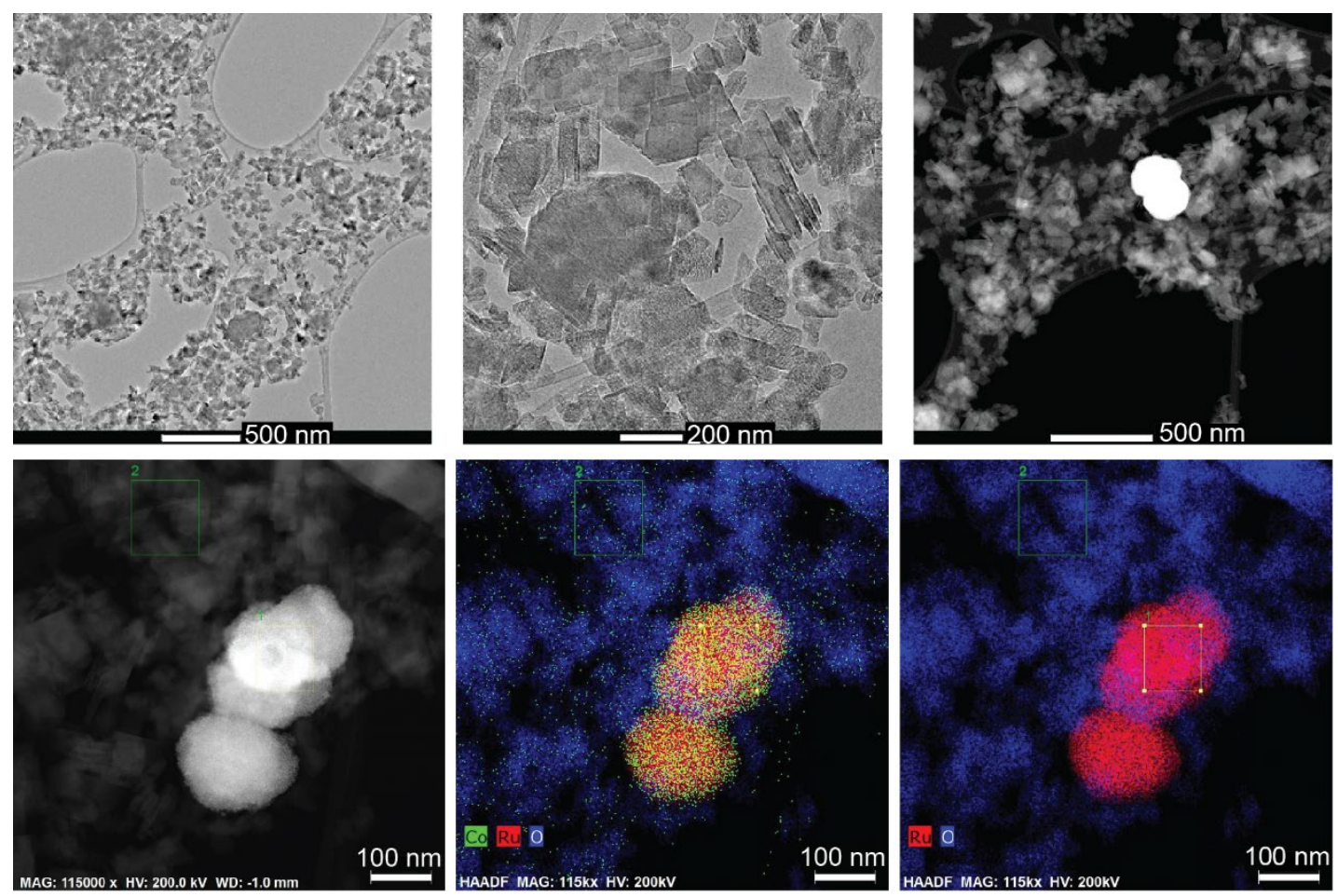

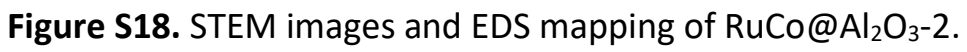

PXRD analysis of RuCo@ $\mathrm{Al}_{2} \mathrm{O}_{3}-1$ and $\mathrm{RuCo@} \mathrm{Al}_{2} \mathrm{O}_{3}-2$ revealed that partial conversion of the $\mathrm{Al}_{2} \mathrm{O}_{3}$ to boehmite $(\mathrm{AlO}(\mathrm{OH}))$ had taken place during nanoparticle synthesis (Figure S19). No structural conversion of the support material was observed in the reported synthesis of $\mathrm{RuCo}_{0} @ \mathrm{Al}_{2} \mathrm{O}_{3} .{ }^{6} \mathrm{~A}$ possible reason for

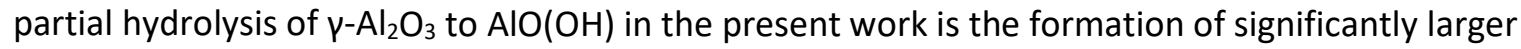

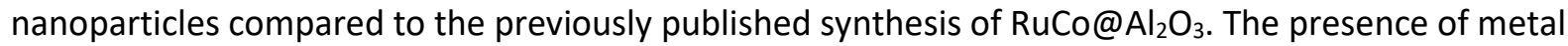
nanoparticles on the surface of $\mathrm{\gamma}-\mathrm{Al}_{2} \mathrm{O}_{3}$ is known to significantly decrease the rate of hydrolysis of $\mathrm{\gamma}$ $\mathrm{Al}_{2} \mathrm{O}_{3}$ to $\mathrm{AlO}(\mathrm{OH})$, which has been attributed to small metal particles blocking surface hydroxyl groups crucial to the hydration reaction..$^{7-8}$ The alloy nanoparticles target here have a significantly higher cobalt

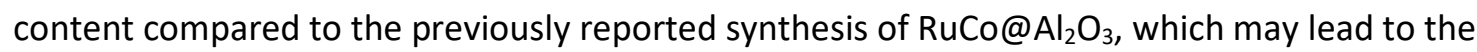
formation of larger RuCo particles that are less able to protect the surface of $\mathrm{\gamma}-\mathrm{Al}_{2} \mathrm{O}_{3}$ from hydrolysis.

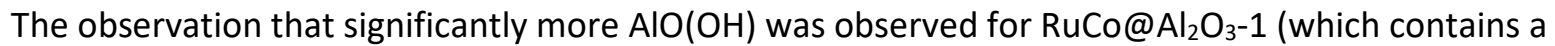

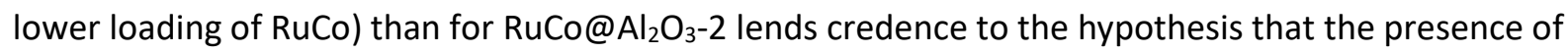
nanoparticles on the surface of the support material protects $\mathrm{\gamma}-\mathrm{Al}_{2} \mathrm{O}_{3}$ from hydrolysis during the synthesis. 


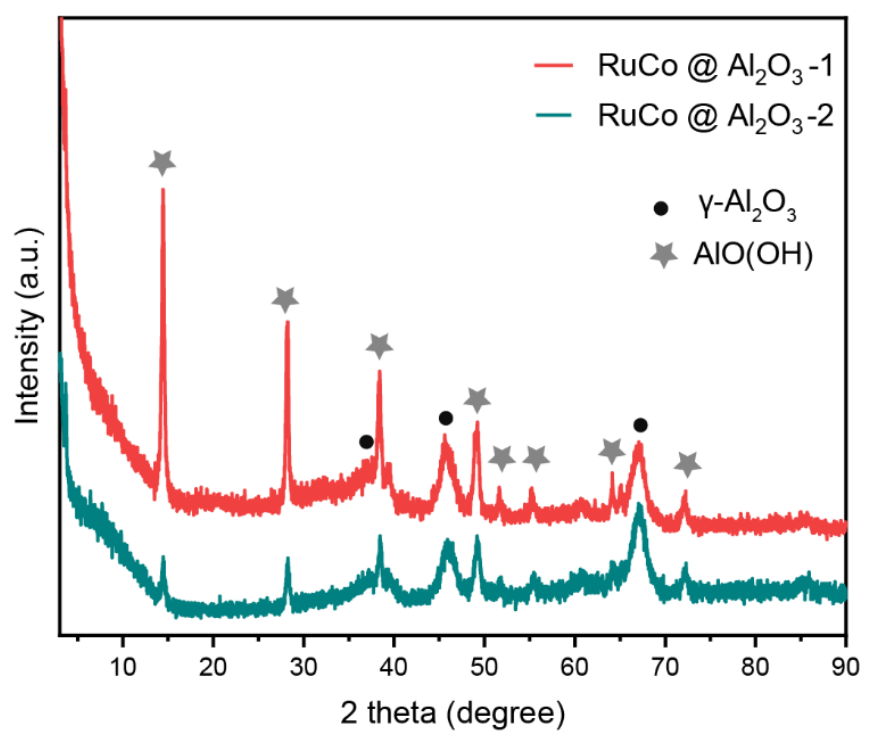

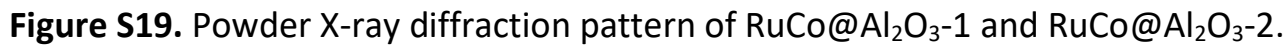

\section{Reaction Conditions for 1-Butanol Upgrading}

Butanol upgrading reaction was conducted in a stainless steel Parr reactor (Parr Instrument Company, Series 4790 pressure vessel systems; $25 \mathrm{~mL}$ capacity vessel with flat PTFE flat gasket for temperatures up to $350^{\circ} \mathrm{C}$ ). The temperature of the reactor was controlled using a reactor controller (Parr Instrument Company, Model 4838) and the pressure within the reaction vessel monitored using the pressure gauge included as a fitting on the reactor head. Under air, a rare earth magnetic stirring bar (Octagon Magnetic stirring bars, Bel-Art) was added to the Parr reactor as well as catalyst 1 . NaOBu in 1-butanol (20 mL of a 2.5-10 mol\% solution) was added to the Parr reactor and the reactor was closed, placed on top of a stirring plate, and heated to $170{ }^{\circ} \mathrm{C}$ using the reactor controller for the specified time (Figure S20). After the reactor was cooled to room temperature, the pressure was released and the reactor opened. Internal standard $\mathrm{m}$-xylene $(50 \mu \mathrm{L}$ ) was added to the crude reaction mixture, followed by acetone (20 $\mathrm{mL}$ ) to precipitate the sodium butyrate side product. The crude reaction mixture was filtered to remove sodium butyrate, which was dried and quantified. The filtrate was neutralized with $\mathrm{AcOH}$ and filtered to remove salts formed during neutralization, and three GC-MS samples were prepared from the neutralized filtrate. 


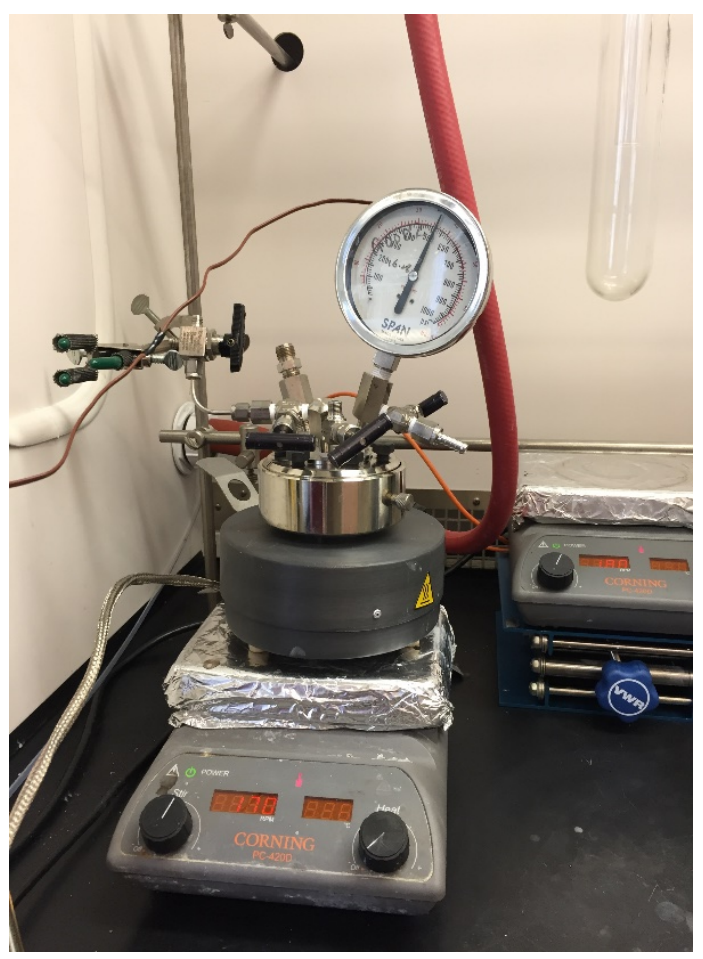

Figure S20. Reaction setup for 1-butanol upgrading reactions.

\section{Preparation of NaOBu Solutions in 1-Butanol}

Sodium butoxide solution for the use in butanol upgrading reactions was prepared by dissolving the requisite amount of sodium metal in ACS grade anhydrous $n-\mathrm{BuOH}$ to obtain a solution containing 10 mol\% NaOBu in $n-\mathrm{BuOH}$. For reactions using smaller amounts of $\mathrm{NaOBu}$ promoter, a mixture of the 10 mol\% $\mathrm{NaOBu}$ solution and pure $n-\mathrm{BuOH}$ was used as the reaction medium.

\section{Calculation of reaction selectivity and turnover numbers}

The selectivity of catalytic reaction was defined as the number of moles of starting alcohols converted into desired products divided by the number of moles of alcohol consumed. Turnover numbers were calculated by dividing the number of moles of 1-butanol consumed by the number of moles of catalytically active metal used. Turnover frequencies were calculated by dividing the turnover numbers by the reaction time (in hours). Site time yields refer to the number of moles of 2-ethylhexanol formed by the number of moles of ruthenium used.

\section{Calculation of the product selectivity and mass balance}

The selectivity for a given reaction product is reported as the ratio of the molar amount of the product of interest (e.g. 2-ethylhexanol) divided by the sum of the molar amounts of all detected products. The mass balance was determined by comparison of the sum of the molar amounts of all detected reaction products with the decrease in the number of moles of butanol over the course of the reaction. 


\section{Analysis of liquid reaction products}

The amount of alcohol product formed was quantified via the addition of a known quantity of m-xylene to the butanol upgrading reaction mixture immediately after the Parr reactor was cooled and opened. Acetone $(30 \mathrm{~mL})$ was added to the reaction mixture before it was filtered to remove the catalyst and any solid side products. The filtered reaction mixture was neutralized with acetic acid and filtered again to remove solids formed during neutralization before three GC-MS sample vials were prepared. FID and mass traces of all three samples were collected and the amount of various liquid products formed was calculated from the peak areas (averaged over three samples). The amounts of products were determined from ratio of their averages peak areas (obtained using the FID detector) and the average peak area determined for the internal standard m-xylene through the use of calibration curves (constructed through analysis of mixtures of known ratios of the respective reaction product and $\mathrm{m}$ xylene). Analysis of the peak areas determined using the GC-MS mass detector only revealed very minor differences to the results obtained using the FID detector.

\section{GC-MS chromatograms of crude reaction mixture}

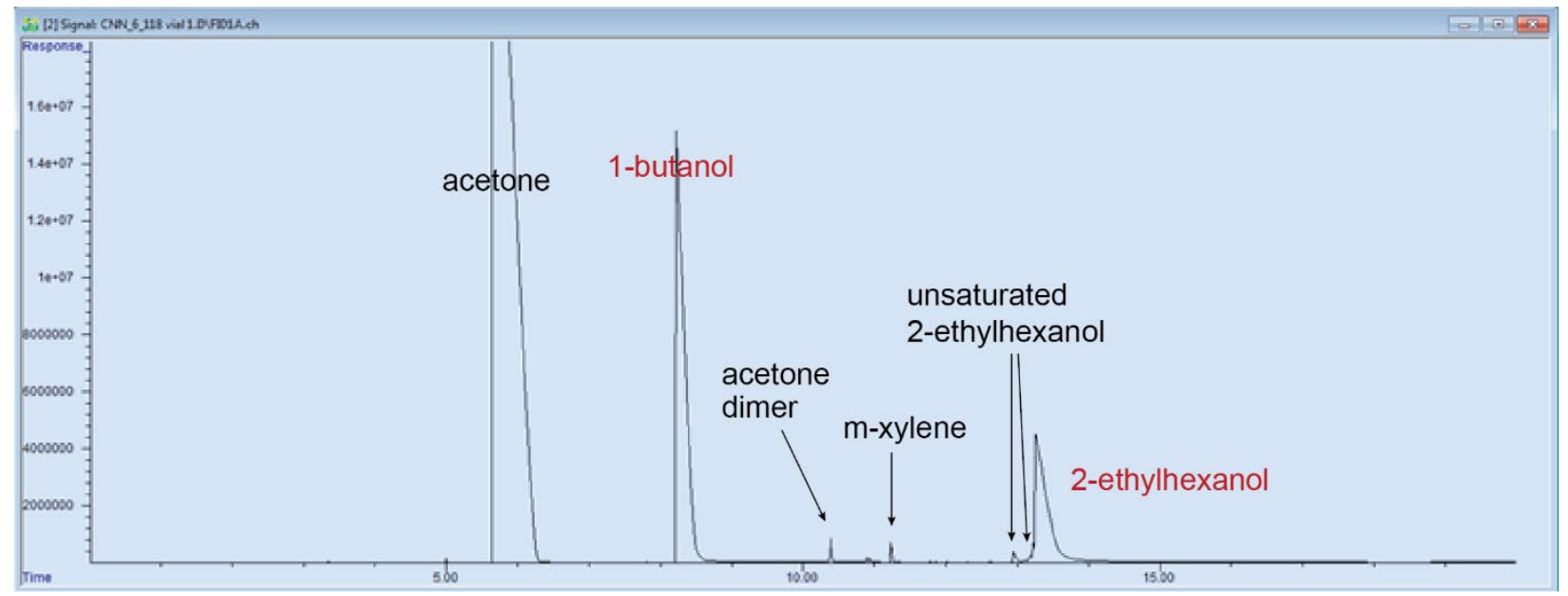

Figure S21. GC-MS chromatogram of 1-butanol upgrading reaction catalyzed by 1. Peak marked 'acetone dimer' corresponds to the aldol condensation product of acetone formed during reaction work-up.

\section{Experimental Procedure and Detailed Results for Experiments in Figure 3}

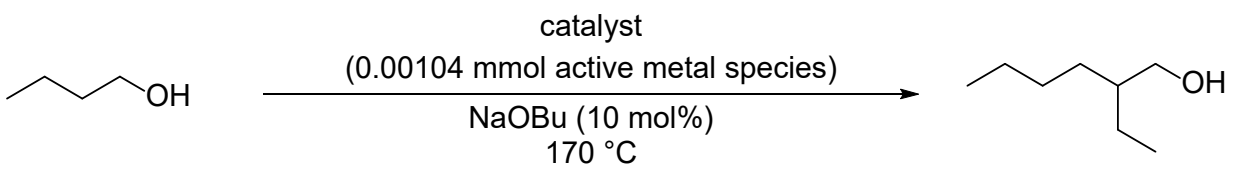

Butanol upgrading reactions were conducted in a stainless steel Parr reactor (Parr Instrument Company, Series 4790 pressure vessel systems; $25 \mathrm{~mL}$ capacity vessel with flat PTFE flat gasket for temperatures up 
to $350^{\circ} \mathrm{C}$ ). The temperature of the reactor was controlled using a reactor controller (Parr Instrument Company, Model 4838) and the pressure within the reaction vessel monitored using the pressure gauge included as a fitting on the reactor head. A rare earth magnetic stirring bar (Octagon Magnetic stirring bars, Bel-Art) was added to the Parr reactor as well the amount of catalyst corresponding to $1.04 \cdot 10^{-3}$ mmol catalytically active metal species. $\mathrm{NaOBu}$ in butanol $(20.0 \mathrm{~mL}$ of a $10 \mathrm{~mol} \%$ solution) was added to the Parr reactor and the reactor was closed, placed on top of a stirring plate, and heated to $170{ }^{\circ} \mathrm{C}$ using the reactor controller for the specified time (see Table S3 and S4). After the reactor was cooled to room temperature, the pressure was released and the reactor opened. Internal standard $\mathrm{m}$-xylene $(50 \mu \mathrm{L})$ was added to the crude reaction mixture, followed by acetone $(20 \mathrm{~mL})$ to precipitate the sodium butanoate side product. The crude reaction mixture was filtered to remove sodium butanoate, which was dried and quantified. The filtrate was neutralized with $\mathrm{AcOH}$ and filtered to remove salts formed during neutralization, and three GC-MS samples were prepared from the neutralized filtrate from which the amounts of Guerbet alcohol, unsaturated $C_{8}$ alcohol and remaining 1-butanol were determined (no other products were detected for reactions described in Figure 3/Table S3 and S4).

Due to the significantly higher activity of 1 , the reaction time for this catalyst was curtailed to $14.5 \mathrm{~h}$ in order to achieve 1-butanol conversions comparable to those obtained with the most active among the remaining catalysts. The highest conversions were obtained with Ru@C and Rh@C, but for both these samples not all mass could be accounted for at the end of the reaction (mass balance (Ru@C)=0.94; mass balance $(\mathrm{Rh} @ \mathrm{C})=0.93)$.

\begin{tabular}{|c|c|c|c|c|c|c|c|c|c|}
\hline Catalyst & $\begin{array}{c}\text { Time } \\
{[\mathrm{h}]}\end{array}$ & $\begin{array}{c}\text { TON } \\
{\left[\mathrm{Ru}^{-1}\right]}\end{array}$ & $\begin{array}{c}\text { TOF } \\
{\left[R u^{-1} \mathbf{h}^{-1}\right]}\end{array}$ & Conv. & $\begin{array}{c}\text { Mass } \\
\text { balance }\end{array}$ & $\begin{array}{l}\text { Sel } \\
(\mathbf{G})^{c}\end{array}$ & $\begin{array}{l}\text { Sel } \\
\text { (U) }\end{array}$ & $\begin{array}{l}\text { Sel } \\
\text { (C) }\end{array}$ & $\begin{array}{c}\text { Product } \\
{[\mu \mathrm{L}]}\end{array}$ \\
\hline $\mathrm{Ru}\left(\mathrm{PPh}_{3}\right)_{2} \mathrm{Cl}_{2}$ & 21.5 & 64480 & 2999 & 0.38 & 0.91 & 0.73 & 0.05 & 0.22 & 3837 \\
\hline $\mathrm{IrCl}_{3}$, phen $^{a}$ & 21.5 & 58564 & 2723 & 0.36 & 0.91 & 0.66 & 0.08 & 0.26 & 3145 \\
\hline$[\operatorname{Ir}(C O D) C l]_{2}$ & 21.5 & 33821 & 1573 & 0.16 & 0.99 & 0.68 & 0.11 & 0.21 & 1876 \\
\hline$\left[\mathrm{Rh}(\mathrm{COE})_{2} \mathrm{Cl}\right]_{2}$ & 21.5 & 52600 & 2447 & 0.34 & 0.90 & 0.65 & 0.08 & 0.27 & 2794 \\
\hline$\left[\mathrm{Rh}(\mathrm{COE})_{2} \mathrm{Cl}\right]_{2}, d p p m^{b}$ & 21.5 & 22951 & 1067 & 0.09 & 1.02 & 0.54 & 0.23 & 0.22 & 1017 \\
\hline 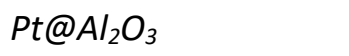 & 21.5 & 49272 & 2292 & 0.30 & 0.93 & 0.66 & 0.08 & 0.26 & 2648 \\
\hline Ir@N-doped-C & 21.5 & 60496 & 2814 & 0.33 & 0.98 & 0.68 & 0.07 & 0.25 & 3356 \\
\hline$P d @ C$ & 20.25 & 66035 & 3261 & 0.34 & 0.96 & 0.73 & 0.03 & 0.23 & 3930 \\
\hline Rh@C & 21.5 & 72668 & 3380 & 0.43 & 0.93 & 0.72 & 0.06 & 0.22 & 4243 \\
\hline Ru@C & 21.5 & 73854 & 3435 & 0.43 & 0.94 & 0.71 & 0.06 & 0.23 & 4258 \\
\hline RuCo@N-doped-C & 21.5 & 59272 & 2757 & 0.37 & 0.93 & 0.68 & 0.07 & 0.26 & 3263 \\
\hline 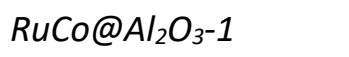 & 21.5 & 53534 & 2490 & 0.25 & 1.01 & 0.67 & 0.07 & 0.26 & 2925 \\
\hline 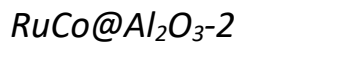 & 21.5 & 59314 & 2759 & 0.34 & 0.96 & 0.68 & 0.06 & 0.25 & 3301 \\
\hline RuCo@C-4 & 21.5 & 58173 & 2706 & 0.31 & 0.98 & 0.67 & 0.07 & 0.26 & 3183 \\
\hline RuCo@C-3 & 22.5 & 63801 & 2836 & 0.33 & 0.99 & 0.69 & 0.07 & 0.24 & 3600 \\
\hline 1 & 14.5 & 76928 & 5305 & 0.37 & 1.02 & 0.77 & 0.04 & 0.19 & 4821 \\
\hline
\end{tabular}

Table S3. Butanol upgrading with different catalysts using 10 mol\% NaOBu. ${ }^{9}$ phen = phenanthroline; 6.0 equivalents of ligand used relative to $\mathrm{IrCl}_{3}$. ${ }^{\mathrm{b}} \mathrm{dppm}=$ bis(diphenylphosphino)methane; 1.0 equivalents of ligand were used relative to $\left[\mathrm{Rh}(\mathrm{COE})_{2} \mathrm{Cl}\right]_{2}$. 'Selectivity for desired Guerbet alcohol dSelectivity for unsaturated Guerbet alcohol 'Selectivity for sodium carboxylate (sodium butanoate). 
catalyst
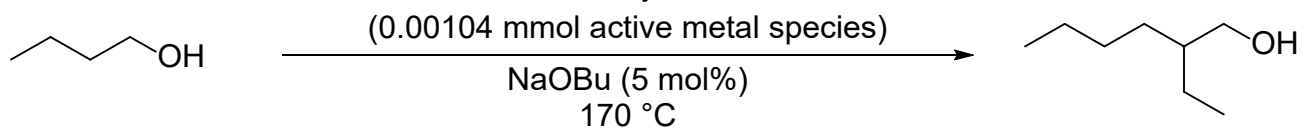

Experiments were conducted analogously to the procedure described above, except that $20.0 \mathrm{~mL}$ of a 5 mol\% solution of $\mathrm{NaOBu}$ in butanol was used as a base promoter. The reaction time used in the 1butanol upgrading with 1 was chosen so that the conversion obtained (0.29) was comparable to the highest conversion achieved with any of the remaining catalysts $\left(\mathrm{Ru}\left(\mathrm{PPh}_{3}\right)_{3} \mathrm{Cl}_{2}, 0.28\right)$.

\begin{tabular}{|c|c|c|c|c|c|c|c|c|c|}
\hline Catalyst & $\begin{array}{c}\text { Time } \\
{[\mathrm{h}]}\end{array}$ & $\begin{array}{c}\text { TON } \\
{\left[\mathrm{Ru}^{-1}\right]}\end{array}$ & $\begin{array}{c}\text { TOF } \\
{\left[\mathrm{Ru}^{-1} \mathrm{~h}^{-1}\right]}\end{array}$ & Conv. & $\begin{array}{c}\text { Mass } \\
\text { balance }\end{array}$ & Sel $(G)^{b}$ & Sel (U)c & $\begin{array}{l}\text { Sel } \\
\text { (C) }^{d}\end{array}$ & $\begin{array}{c}\text { Product } \\
{[\mu \mathrm{L}]}\end{array}$ \\
\hline $\mathrm{Ru}\left(\mathrm{PPh}_{3}\right)_{2} \mathrm{Cl}_{2}$ & 20.75 & 46736 & 2252 & 0.28 & 0.96 & 0.77 & 0.18 & 0.05 & 2908 \\
\hline $\mathrm{IrCl}_{3}$, phen ${ }^{a}$ & 20.25 & 30464 & 1504 & 0.14 & 1.01 & 0.72 & 0.16 & 0.13 & 1774 \\
\hline$[\operatorname{Ir}(C O D) C l]_{2}$ & 20.25 & 15823 & 781 & 0.19 & 0.88 & 0.58 & 0.23 & 0.19 & 749 \\
\hline$\left[R h(C O E){ }_{2} \mathrm{Cl}\right]_{2}$ & 20.25 & 20857 & 1030 & 0.26 & 0.83 & 0.56 & 0.24 & 0.21 & 942 \\
\hline $\mathrm{Pt} @ \mathrm{Al}_{2} \mathrm{O}_{3}$ & 20.5 & 41710 & 2035 & 0.21 & 0.99 & 0.73 & 0.15 & 0.12 & 2486 \\
\hline Ir@N-doped-C & 20.5 & 45620 & 2225 & 0.19 & 1.04 & 0.72 & 0.15 & 0.13 & 2683 \\
\hline Pd@C & 21 & 6836 & 326 & 0.04 & 1.00 & 0.45 & 0.35 & 0.20 & 248 \\
\hline Ru@C & 20.5 & 43020 & 2099 & 0.27 & 0.95 & 0.72 & 0.16 & 0.11 & 2531 \\
\hline RuCo@N-doped-C & 20.5 & 39633 & 1933 & 0.18 & 1.02 & 0.72 & 0.17 & 0.10 & 2328 \\
\hline 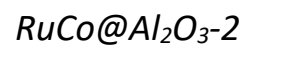 & 20.5 & 35021 & 1708 & 0.17 & 1.01 & 0.74 & 0.15 & 0.11 & 2099 \\
\hline RuCo@C-4 & 20.5 & 42292 & 2063 & 0.19 & 1.02 & 0.75 & 0.15 & 0.09 & 2593 \\
\hline RuCo@C-3 & 20.5 & 43404 & 2117 & 0.19 & 1.02 & 0.77 & 0.13 & 0.10 & 2711 \\
\hline 1 & 14.5 & 63893 & 4406 & 0.29 & 1.03 & 0.83 & 0.09 & 0.07 & 4330 \\
\hline
\end{tabular}

Table S4. Butanol upgrading with different catalysts using 5 mol\% NaOBu. ${ }^{\text {aphen }}=$ phenanthroline; 6.0 equivalents of ligand used relative to $\mathrm{IrCl}_{3}$. ' $S$ Selectivity for desired Guerbet alcohol 'Selectivity for unsaturated Guerbet alcohol belectivity for sodium carboxylate (sodium butanoate). 


\section{Experimental Procedure and Detailed Results for Experiments in Table 1}

Reactions were performed according to the general procedure for alcohol upgrading reactions using the amount and batch of catalyst as described in the respective entry.

Optimized conditions for butanol (Entry 1)

$\mathrm{Ru}(\mathrm{COD}) \mathrm{Cl}_{2} @ \mathrm{MFU}-1$ (Ru : Co ratio = $\left.0.0044: 1.000\right)$ equivalent to $[\mathrm{Ru}]=3.3 \cdot 10^{-5} \mathrm{mmol}, 5 \mathrm{~mol} \% \mathrm{NaOBu}$ in butanol $(20.0 \mathrm{~mL}), 15.5 \mathrm{~h}$ reaction time

\begin{tabular}{|c|c|c|c|c|c|c|c|c|c|c|}
\hline $\begin{array}{c}\text { Ru } \\
\text { ligand }\end{array}$ & $\begin{array}{l}\mathrm{NaOBu} \\
\text { [mol\%] }\end{array}$ & $\begin{array}{c}\text { Time } \\
{[\mathrm{h}]}\end{array}$ & $\begin{array}{c}\text { TON } \\
{\left[\mathrm{Ru}^{-1}\right]}\end{array}$ & $\begin{array}{c}\text { TOF } \\
{\left[R u^{-1} h^{-1}\right]}\end{array}$ & Conv. & $\begin{array}{c}\text { Mass } \\
\text { balance }\end{array}$ & $\begin{array}{c}\text { Sel. } \\
\text { (Guerbet) }\end{array}$ & $\begin{array}{l}\text { Sel. } \\
\text { (unsat.) }\end{array}$ & $\begin{array}{c}\text { Sel } \\
\text { (Carbox.) }\end{array}$ & $\begin{array}{c}\text { Product } \\
{[\mu \mathrm{L}]}\end{array}$ \\
\hline$C O D$ & $5 \%$ & 15.5 & 1770504 & 114226 & 0.31 & 0.97 & 0.81 & 0.11 & 0.08 & 3722 \\
\hline
\end{tabular}

\section{Repetition of entry 1 with recovered catalyst (Entry 2)}

$\mathrm{Ru}(\mathrm{COD}) \mathrm{Cl}_{2} @ \mathrm{MFU}-1$ (recovered catalyst), $5 \mathrm{~mol} \% \mathrm{NaOBu}$ in butanol $(20.0 \mathrm{~mL}), 15.5 \mathrm{~h}$ reaction time

\begin{tabular}{|c|c|c|c|r|r|r|r|r|r|r|}
$\begin{array}{c}\text { Ru } \\
\text { ligand }\end{array}$ & $\begin{array}{c}\text { NaOBu } \\
{[\mathrm{mol} \%]}\end{array}$ & $\begin{array}{c}\text { Time } \\
{[\mathrm{h}]}\end{array}$ & $\begin{array}{c}\text { TON } \\
{\left[\mathrm{Ru}^{-1}\right]}\end{array}$ & $\begin{array}{c}\text { TOF } \\
{\left[\mathrm{Ru}^{-1} \mathbf{h}^{-1}\right]}\end{array}$ & Conv. & $\begin{array}{c}\text { Mass } \\
\text { balance }\end{array}$ & $\begin{array}{c}\text { Sel. } \\
\text { (Guerbet) }\end{array}$ & $\begin{array}{c}\text { Sel. } \\
\text { (unsat.) }\end{array}$ & $\begin{array}{c}\text { Sel } \\
\text { (Carbox.) }\end{array}$ & $\begin{array}{c}\text { Product } \\
{[\mu \mathrm{L}]}\end{array}$ \\
\hline COD & $\mathbf{5 \%}$ & 15.5 & 1047086 & $\mathbf{6 7 5 5 4}$ & 0.14 & 1.03 & 0.71 & 0.19 & 0.10 & 1940 \\
\hline
\end{tabular}

\section{Repetition of Entry 1 using $\mathrm{K}_{3} \mathrm{PO}_{4}$ instead of NaOEt as a base promoter (Entry 3)}

$\mathrm{Ru}(\mathrm{COD}) \mathrm{Cl}_{2} @ \mathrm{MFU}-1(\mathrm{Ru}:$ Co ratio $=0.0044: 1.000)$ equivalent to $[\mathrm{Ru}]=3.3 \cdot 10^{-5} \mathrm{mmol}, 5 \mathrm{~mol} \% \mathrm{~K}_{3} \mathrm{PO}_{4}$ in butanol $(20.0 \mathrm{~mL}), 15.5 \mathrm{~h}$ reaction time

No sodium carboxylate product was formed when $\mathrm{K}_{3} \mathrm{PO}_{4}$ is used as a base promoter, but small amounts of unsaturated and saturated $\mathrm{C}_{8}$ aldehyde were detected (see Sel. (aldeh.) in Table below as well as Figure S28). For the PXRD pattern of the recovered solid material see Figure S39.

\begin{tabular}{|c|c|c|c|c|c|c|c|c|c|c|}
\hline $\begin{array}{l}\mathrm{Ru} \\
\text { ligand }\end{array}$ & $\begin{array}{l}\mathrm{K}_{3} \mathrm{PO}_{4} \\
{[\mathrm{~mol} \%]}\end{array}$ & $\begin{array}{c}\text { Time } \\
{[\mathrm{h}]}\end{array}$ & $\begin{array}{c}\text { TON } \\
{\left[\mathrm{Ru}^{-1}\right]}\end{array}$ & $\begin{array}{c}\text { TOF } \\
{\left[\mathrm{Ru}^{-1} \mathrm{~h}^{-1}\right]}\end{array}$ & Conv. & $\begin{array}{c}\text { Mass } \\
\text { balance }\end{array}$ & $\begin{array}{c}\text { Sel. } \\
\text { (Guerbet) }\end{array}$ & $\begin{array}{l}\text { Sel. } \\
\text { (unsat.) }\end{array}$ & $\begin{array}{c}\text { Sel } \\
\text { (aldeh.) }\end{array}$ & $\begin{array}{c}\text { Product } \\
{[\mu \mathrm{L}]}\end{array}$ \\
\hline$C O D$ & $5 \%$ & 15.5 & 1051859 & 67862 & 0.20 & 0.96 & 0.80 & 0.16 & 0.04 & 2202 \\
\hline
\end{tabular}

\section{Repetition of Entry 1 using LiOH instead of NaOEt as a base promoter (Entry 4)}

$\mathrm{Ru}(\mathrm{COD}) \mathrm{Cl}_{2} @ \mathrm{MFU}-1$ (Ru : Co ratio = $\left.0.0044: 1.000\right)$ equivalent to $[\mathrm{Ru}]=3.3 \cdot 10^{-5} \mathrm{mmol}, 5 \mathrm{~mol} \% \mathrm{LiOH}$ in butanol $(20.0 \mathrm{~mL}), 15.5 \mathrm{~h}$ reaction time

Small amounts of unsaturated and saturated $\mathrm{C}_{8}$ aldehyde were detected (see Sel. (aldeh.) in Table below as well as Figure S28). For the PXRD pattern of the recovered solid material see Figure S38.

\begin{tabular}{|c|c|c|c|c|c|c|c|c|c|c|}
\hline $\begin{array}{l}\text { Ru } \\
\text { ligand }\end{array}$ & $\begin{array}{c}\text { LiOH } \\
\text { [mol\%] }\end{array}$ & $\begin{array}{c}\text { Time } \\
{[\mathrm{h}]}\end{array}$ & $\begin{array}{c}\text { TON } \\
{\left[\mathrm{Ru}^{-1}\right]}\end{array}$ & $\begin{array}{c}\text { TOF } \\
{\left[\mathrm{Ru}^{-1} \mathbf{h}^{-1}\right]}\end{array}$ & Conv. & $\begin{array}{c}\text { Mass } \\
\text { balance }\end{array}$ & $\begin{array}{c}\text { Sel. } \\
\text { (Guerbet) }\end{array}$ & $\begin{array}{l}\text { Sel. } \\
\text { (unsat.) }\end{array}$ & $\begin{array}{c}\text { Sel } \\
\text { (aldeh.) }\end{array}$ & $\begin{array}{l}\text { Product } \\
{[\mu \mathrm{L}]}\end{array}$ \\
\hline$C O D$ & $5 \%$ & 15.5 & 389854 & 25539 & 0.06 & 0.99 & 0.53 & 0.36 & 0.11 & 544 \\
\hline
\end{tabular}




\section{Conditions for butanol upgrading with high selectivity (Entry 5)}

$\mathrm{Ru}(\mathrm{nbd}) \mathrm{Cl}_{2} @ \mathrm{MFU}-1$ (Ru : $\mathrm{Co}=0.0104: 1.000$ ) equivalent to $[\mathrm{Ru}]=2.75 \cdot 10^{-4} \mathrm{mmol}, 2.5 \mathrm{~mol} \% \mathrm{NaOBu}$ in butanol $(20.0 \mathrm{~mL}), 18 \mathrm{~h}$ reaction time

\begin{tabular}{|c|c|c|c|c|c|c|c|c|c|c|}
\hline $\begin{array}{l}\text { Ru } \\
\text { ligand }\end{array}$ & $\begin{array}{l}\mathrm{NaOBu} \\
\text { [mol\%] }\end{array}$ & $\begin{array}{c}\text { Time } \\
{[\mathrm{h}]}\end{array}$ & $\begin{array}{c}\text { TON } \\
{\left[R^{-1}\right]}\end{array}$ & $\begin{array}{c}\text { TOF } \\
{\left[\mathrm{Ru}^{-1} \mathbf{h}^{-1}\right]}\end{array}$ & Conv. & $\begin{array}{c}\text { Mass } \\
\text { balance }\end{array}$ & $\begin{array}{c}\text { Sel. } \\
\text { (Guerbet) }\end{array}$ & $\begin{array}{l}\text { Sel. } \\
\text { (unsat.) }\end{array}$ & $\begin{array}{c}\text { Sel } \\
\text { (Carbox.) }\end{array}$ & $\begin{array}{c}\text { Product } \\
{[\mu \mathrm{L}]}\end{array}$ \\
\hline$n b d$ & $2.5 \%$ & 18 & 193652 & 10758 & 0.28 & 0.99 & 0.86 & 0.07 & 0.06 & 3589 \\
\hline
\end{tabular}

\section{Conditions for butanol upgrading with high conversion (Entry 6)}

$\mathrm{Ru}(\mathrm{COD}) \mathrm{Cl}_{2} @ \mathrm{MFU}-1$ (Ru : $\left.\mathrm{Co}=0.0044: 1.000\right)$ equivalent to $[\mathrm{Ru}]=2.75 \cdot 10^{-4} \mathrm{mmol}, 10 \mathrm{~mol} \% \mathrm{NaOBu}$ in butanol $(21.0 \mathrm{~mL}), 14 \mathrm{~h}$ reaction time

\begin{tabular}{|c|c|c|c|c|r|r|r|r|r|r|}
$\begin{array}{c}\text { Ru } \\
\text { ligand }\end{array}$ & $\begin{array}{c}\text { NaOBu } \\
{[\mathrm{mol} \%]}\end{array}$ & $\begin{array}{c}\text { Time } \\
{[\mathrm{h}]}\end{array}$ & $\begin{array}{c}\text { TON } \\
{\left[\mathrm{Ru}^{-1}\right]}\end{array}$ & $\begin{array}{c}\text { TOF } \\
{\left[\mathrm{Ru}^{-1} \mathbf{h}^{-1}\right]}\end{array}$ & Conv. & $\begin{array}{c}\text { Mass } \\
\text { balance }\end{array}$ & $\begin{array}{c}\text { Sel. } \\
\text { (Guerbet) }\end{array}$ & $\begin{array}{c}\text { Sel. } \\
\text { (unsat.) }\end{array}$ & $\begin{array}{c}\text { Sel } \\
\text { (Carbox.) }\end{array}$ & $\begin{array}{c}\text { Product } \\
{[\mu \mathrm{L}]}\end{array}$ \\
\hline COD & $\mathbf{1 0 \%}$ & 14 & 305642 & $\mathbf{2 1 8 3 2}$ & 0.39 & 0.99 & 0.76 & 0.05 & 0.19 & 4959 \\
\hline
\end{tabular}

\section{Comparison of catalyst loadings for butanol upgrading (Entry 7)}

$\mathrm{Ru}(\mathrm{COD}) \mathrm{Cl}_{2} @ \mathrm{MFU}-1$ (Ru : $\left.\mathrm{Co}=0.0044: 1.000\right)$ equivalent to $[\mathrm{Ru}]=2.75 \cdot 10^{-4} \mathrm{mmol}, 5 \mathrm{~mol} \% \mathrm{NaOBu}$ in butanol $(20.0 \mathrm{~mL}), 15.5 \mathrm{~h}$ reaction time

\begin{tabular}{|c|c|c|c|c|c|c|c|c|c|c|}
\hline $\begin{array}{l}\text { Ru } \\
\text { ligand }\end{array}$ & $\begin{array}{l}\mathrm{NaOBu} \\
\text { [mol\%] }\end{array}$ & $\begin{array}{c}\text { Time } \\
\text { [h] }\end{array}$ & $\begin{array}{c}\text { TON } \\
{\left[\mathrm{Ru}^{-1}\right]}\end{array}$ & $\begin{array}{c}\text { TOF } \\
{\left[\mathrm{Ru}^{-1} \mathbf{h}^{-1}\right]}\end{array}$ & Conv. & $\begin{array}{c}\text { Mass } \\
\text { balance }\end{array}$ & $\begin{array}{c}\text { Sel. } \\
\text { (Guerbet) }\end{array}$ & $\begin{array}{l}\text { Sel. } \\
\text { (unsat.) }\end{array}$ & $\begin{array}{c}\text { Sel } \\
\text { (Carbox.) }\end{array}$ & $\begin{array}{l}\text { Product } \\
{[\mu \mathrm{L}]}\end{array}$ \\
\hline$C O D$ & $5 \%$ & 15.5 & 237713 & 15336 & 0.30 & 0.99 & 0.84 & 0.06 & 0.11 & 4283 \\
\hline
\end{tabular}

\section{Repetition of entry 7 with recovered catalyst (Entry 8)}

$\mathrm{Ru}(\mathrm{COD}) \mathrm{Cl}_{2} @ \mathrm{MFU}-1$ (recovered catalyst), 5 mol\% NaOBu in butanol $(20.0 \mathrm{~mL}), 15.5 \mathrm{~h}$ reaction time

\begin{tabular}{|c|c|c|c|c|c|c|c|c|c|c|}
\hline $\begin{array}{l}\text { Ru } \\
\text { ligand }\end{array}$ & $\begin{array}{l}\mathrm{NaOBu} \\
\text { [mol\%] }\end{array}$ & $\begin{array}{c}\text { Time } \\
{[\mathrm{h}]}\end{array}$ & $\begin{array}{c}\text { TON } \\
{\left[R u^{-1}\right]}\end{array}$ & $\begin{array}{c}\text { TOF } \\
{\left[\mathrm{Ru}^{-1} \mathrm{~h}^{-1}\right]}\end{array}$ & Conv. & $\begin{array}{c}\text { Mass } \\
\text { balance }\end{array}$ & $\begin{array}{c}\text { Sel. } \\
\text { (Guerbet) }\end{array}$ & $\begin{array}{l}\text { Sel. } \\
\text { (unsat.) }\end{array}$ & $\begin{array}{c}\text { Sel } \\
\text { (Carbox.) }\end{array}$ & $\begin{array}{c}\text { Product } \\
{[\mu \mathrm{L}]}\end{array}$ \\
\hline$C O D$ & $5 \%$ & 15.5 & 150303 & 9697 & 0.19 & 1.01 & 0.72 & 0.16 & 0.12 & 2335 \\
\hline
\end{tabular}

\section{Repetition of Entry 7 using $\mathrm{NaOH}$ instead of NaOEt as a base promoter (Entry 9)}

$\mathrm{Ru}(\mathrm{COD}) \mathrm{Cl}_{2} @ \mathrm{MFU}-1$ (Ru : $\mathrm{Co}=0.0044: 1.000$ ) equivalent to $[\mathrm{Ru}]=2.75 \cdot 10^{-4} \mathrm{mmol}, 5 \mathrm{~mol} \% \mathrm{NaOH}$ in 1 butanol $(20.0 \mathrm{~mL}), 15.5 \mathrm{~h}$ reaction time

\begin{tabular}{|c|c|c|c|c|c|c|c|c|c|c|}
\hline $\begin{array}{c}\text { Ru } \\
\text { ligand }\end{array}$ & $\begin{array}{c}\mathrm{NaOH} \\
{[\mathrm{mol} \%]}\end{array}$ & $\begin{array}{c}\text { Time } \\
{[\mathrm{h}]}\end{array}$ & $\begin{array}{c}\text { TON } \\
{\left[R u^{-1}\right]}\end{array}$ & $\begin{array}{c}\text { TOF } \\
{\left[R u^{-1} h^{-1}\right]}\end{array}$ & Conv. & $\begin{array}{c}\text { Mass } \\
\text { balance }\end{array}$ & $\begin{array}{c}\text { Sel. } \\
\text { (Guerbet) }\end{array}$ & $\begin{array}{l}\text { Sel. } \\
\text { (unsat.) }\end{array}$ & $\begin{array}{c}\text { Sel } \\
\text { (Carbox.) }\end{array}$ & $\begin{array}{c}\text { Product } \\
{[\mu \mathrm{L}]}\end{array}$ \\
\hline$C O D$ & $5 \%$ & 15.5 & 119453 & 7707 & 0.16 & 0.99 & 0.69 & 0.16 & 0.15 & 1762 \\
\hline
\end{tabular}

\section{Repetition of Entry 7 using $\mathrm{K}_{3} \mathrm{PO}_{4}$ instead of NaOEt as a base promoter (Entry 10)}

$\mathrm{Ru}(\mathrm{COD}) \mathrm{Cl}_{2} @ \mathrm{MFU}-1$ (Ru : $\mathrm{Co}=0.0044: 1.000$ ) equivalent to $[\mathrm{Ru}]=2.75 \cdot 10^{-4} \mathrm{mmol}, 5 \mathrm{~mol} \% \mathrm{~K}_{3} \mathrm{PO}_{4}$ in 1 butanol $(20.0 \mathrm{~mL}), 15.5 \mathrm{~h}$ reaction time 
No sodium carboxylate product was formed when $\mathrm{K}_{3} \mathrm{PO}_{4}$ is used as a base promoter, but small amounts of unsaturated and saturated $\mathrm{C}_{8}$ aldehyde were detected (see Sel (aldeh.) in Table below and Figure S28).

\begin{tabular}{|c|c|c|c|c|c|c|c|c|c|c|}
\hline Ru & $\begin{array}{c}\mathrm{K}_{3} \mathrm{PO}_{4} \\
{[\mathrm{~mol} \%]}\end{array}$ & $\begin{array}{l}\text { Time } \\
\text { [h] }\end{array}$ & $\begin{array}{c}\text { TON } \\
{\left[\mathrm{Ru}^{-1}\right]}\end{array}$ & $\begin{array}{c}\text { TOF } \\
{\left[R^{-1} \mathbf{h}^{-1}\right]}\end{array}$ & Conv. & & $\begin{array}{c}\text { Sel. } \\
\text { (Guerbet) }\end{array}$ & $\begin{array}{l}\text { Sel. } \\
\text { (unsat.) }\end{array}$ & $\begin{array}{c}\text { Sel } \\
\text { (aldeh.) }\end{array}$ & $\begin{array}{l}\text { Product } \\
{[\mu L]}\end{array}$ \\
\hline$C O D$ & $5 \%$ & 15.5 & 129614 & 8362 & 0.21 & 0.95 & 0.78 & 0.17 & 0.05 & 2173 \\
\hline
\end{tabular}

\section{Effect of catalyst loading}
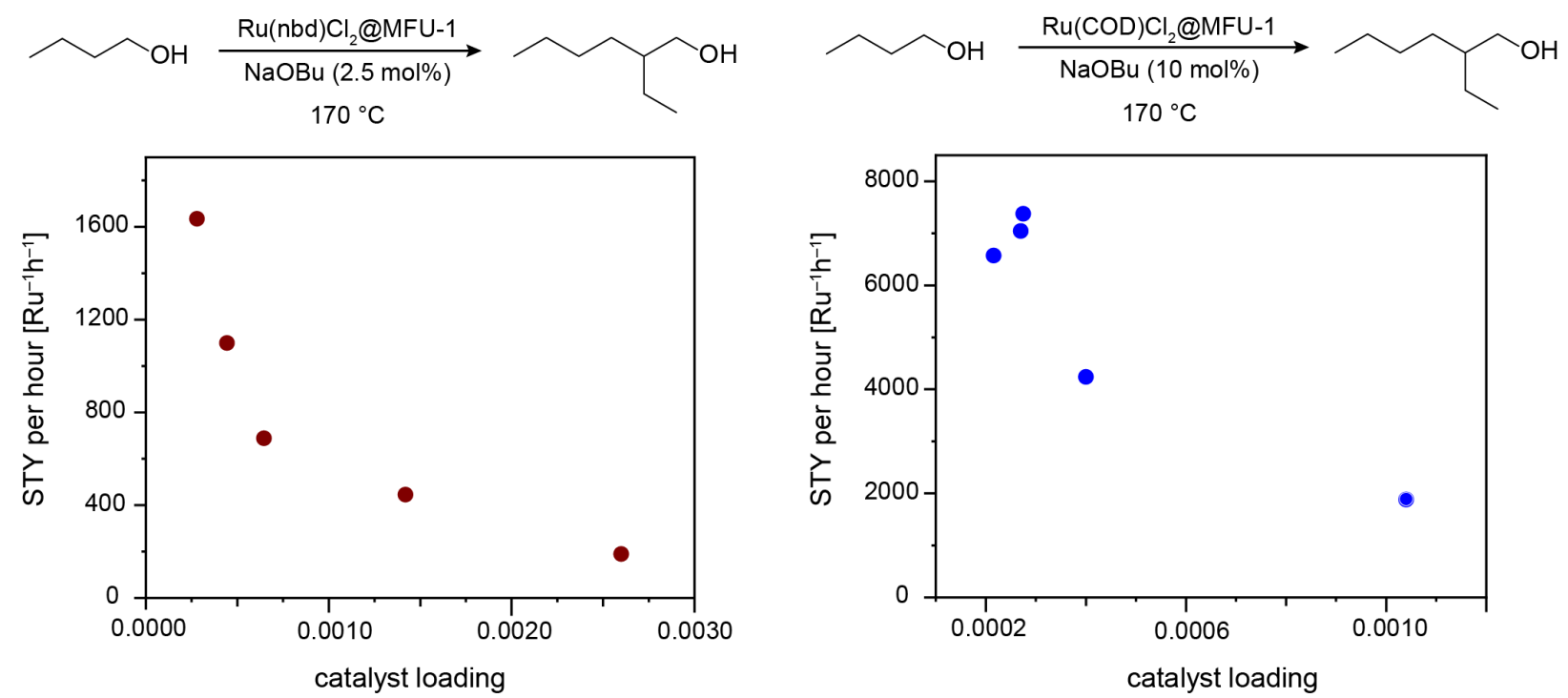

Figure S22. Effect of catalyst loading on the site time yield (STY) for 2-ethylhexanol formation $\left[\mathrm{Ru}^{-1} \mathrm{~h}^{-1}\right]$ in butanol upgrading reactions with 1 evaluated using either $2.5 \mathrm{~mol} \%$ (left) or $10 \mathrm{~mol} \%$ (right) NaOBu as a co-catalyst.

The effect of catalyst concentration for butanol upgrading reaction with $\mathrm{Ru}(\mathrm{nbd}) \mathrm{Cl}_{2} @ \mathrm{MFU}-1$ using 2.5 mol\% NaOBu co-catalyst loading was evaluated after 39-41 hours (Figure S22, left panel and Table S5).

\begin{tabular}{|c|c|c|c|c|c|c|c|c|c|c|c|}
\hline Run & $\begin{array}{c}{[\mathrm{Ru}]} \\
{[\mathrm{mmol}]}\end{array}$ & $\mathrm{Ru}: \mathrm{Co}$ & $\begin{array}{c}\text { Time } \\
{[\mathrm{h}]}\end{array}$ & $\begin{array}{c}S T Y / h^{a} \\
{\left[R u^{-1} h^{-1}\right]}\end{array}$ & $\begin{array}{c}\text { TON } \\
{\left[R u^{-1}\right]}\end{array}$ & $\begin{array}{c}\text { TOF } \\
{\left[R u^{-1} h^{-1}\right]}\end{array}$ & Conv & $\begin{array}{c}\text { mass } \\
\text { balance }\end{array}$ & $\begin{array}{l}\text { Sel. } \\
\text { Guer. }\end{array}$ & $\begin{array}{l}\text { Sel. } \\
\text { Uns. }\end{array}$ & $\begin{array}{l}\text { Sel. } \\
\text { Carb. }\end{array}$ \\
\hline 1 & 0.00028 & 0.014 & 39.5 & 1635 & 177465 & 4492 & 0.24 & 0.99 & 0.82 & 0.13 & 0.05 \\
\hline 2 & 0.00044 & 0.010 & 40 & 1099 & 109798 & 2744 & 0.23 & 0.99 & 0.89 & 0.06 & 0.05 \\
\hline 3 & 0.00065 & 0.049 & 39 & 689 & 64997 & 1667 & 0.19 & 1.01 & 0.78 & 0.15 & 0.07 \\
\hline 4 & 0.00142 & 0.049 & 39 & 445 & n.d. & n.d. & n.d. & n.d. & n.d. & n.d. & n.d. \\
\hline 5 & 0.00260 & 0.049 & 41 & 189 & 18420 & 482 & 0.23 & 1.00 & 0.79 & 0.14 & 0.05 \\
\hline
\end{tabular}

Table S5. Butanol upgrading reactions catalyzed by varying amounts of $\mathrm{Ru}(\mathrm{nbd}) \mathrm{Cl}_{2} @ \mathrm{MFU}-1$ and 2.5 mol\% NaOBu promoter. ${ }^{a}$ Values are averages of the values obtained using the FID detector (results obtained using the mass detector on the GC-MS instrument differed very insignificantly from those obtained using the FID detector). For both detection by mass, and detection by FID, the values of three independent samples collected from the reaction mixture were averaged. 
The effect of catalyst concentration on butanol upgrading reactions with Ru(COD)Cl ${ }_{2} @ M F U-1$ using 10 mol\% NaOBu co-catalyst loading was evaluated after 14-14.5 hours (Figure S22, right panel and Table S6). The amount of ruthenium incorporated into the MOF pores to generate the Ru@MOF precatalyst (indicated in Table $\mathrm{S} 6$ as the Ru : Co ratio, which was determined for all catalyst batches prepared using ICP-MS) does not have a substantial effect on the STY for 2-ethylhexanol (Table S6, entries 1 and 2, as well as 4 and 5).

\begin{tabular}{|c|c|c|c|c|c|c|c|c|c|c|c|}
\hline Run & $\begin{array}{c}{[\mathrm{Ru}]} \\
{[\mathrm{mmol}]}\end{array}$ & Ru : Co & $\begin{array}{c}\text { Time } \\
{[\mathrm{h}]}\end{array}$ & $\begin{array}{c}\mathrm{STY} / \mathrm{h}^{\mathrm{a}} \\
{\left[\mathrm{Ru}^{-1} \mathrm{~h}^{-1}\right]}\end{array}$ & $\begin{array}{c}\text { TON } \\
{\left[\mathrm{Ru}^{-1}\right]}\end{array}$ & $\begin{array}{c}\text { TOF } \\
{\left[\mathrm{Ru}^{-1} \mathbf{h}^{-1}\right]}\end{array}$ & Conv & $\begin{array}{c}\text { mass } \\
\text { balance }\end{array}$ & $\begin{array}{l}\text { Sel. } \\
\text { Guer. }\end{array}$ & $\begin{array}{l}\text { Sel. } \\
\text { Uns. }\end{array}$ & $\begin{array}{l}\text { Sel. } \\
\text { Carb. }\end{array}$ \\
\hline 1 & 0.00104 & 0.008 & 14.5 & 1881 & n.d. & n.d. & n.d. & n.d. & n.d. & n.d. & n.d. \\
\hline 2 & 0.00104 & 0.014 & 14.5 & 1890 & 62194 & 4289 & 0.36 & 1.02 & 0.77 & 0.04 & 0.19 \\
\hline 3 & 0.00040 & 0.014 & 14 & 4240 & 138676 & 9905 & 0.34 & 1.00 & 0.75 & 0.05 & 0.20 \\
\hline 4 & 0.000275 & 0.004 & 14 & 7376 & 241843 & 17274 & 0.39 & 0.99 & 0.76 & 0.05 & 0.19 \\
\hline 5 & 0.000270 & 0.014 & 14 & 7041 & n.d. & n.d. & n.d. & n.d. & n.d. & n.d. & n.d. \\
\hline 6 & 0.000216 & 0.018 & 14.5 & 6571 & 242571 & 16729 & 0.27 & 0.99 & 0.73 & 0.10 & 0.17 \\
\hline
\end{tabular}

Table S6. Butanol upgrading reactions catalyzed by varying amounts of $\mathrm{Ru}(\mathrm{nbd}) \mathrm{Cl}_{2} @ M F U-1$ and 10 mol\%

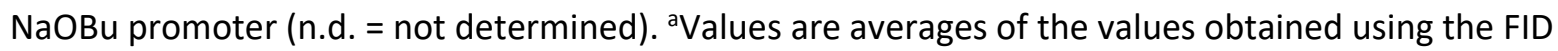
detector (results obtained using the mass detector on the GC-MS instrument differed very insignificantly from those obtained using the FID detector). For both detection by mass, and detection by FID, the values of three independent samples collected from the reaction mixture were averaged.

\section{Hot filtration}

\section{Experimental Details for Figure 4}

Potential leaching of catalytically active species from either 1 or RuCo on other supports was investigated by performing 1-butanol upgrading using the same conditions as those used to collect the data reported in Figure 4 (see Table S7). However, a lower catalyst loading was used for 1 to ensure that a comparable conversion to 2-ethylhexanol had been achieved for catalysts tested after $14 \mathrm{~h}(\mathbf{1})$ or 14.5 $\mathrm{h}$ (other catalysts), when the solid catalyst was removed by filtration. Following the removal of the majority of the solid catalyst as well as the sodium butanoate side product, the liquid was filtered three times using a filter that does not permit the passage of particles $>200 \mathrm{~nm}$. The liquid thus obtained was placed inside a clean Parr reactor and heated to $170^{\circ} \mathrm{C}$ for an additional $4 \mathrm{~h}$ (1) or $6 \mathrm{~h}$ (other catalysts). The amount of product formed was determined both before and after the second time the liquid was heated to $170^{\circ} \mathrm{C}$.

\begin{tabular}{|c|c|c|c|c|c|}
\hline & $\begin{array}{c}\mathrm{Ru} \\
\text { loading }^{\mathrm{a}}\end{array}$ & Ru : Co & $\begin{array}{c}\mathrm{Ru} \\
{[\mathrm{mmol}]^{\mathrm{b}}}\end{array}$ & $\begin{array}{l}\text { 2-ethylhexanol (before } \\
\text { filtration) [mmol] }\end{array}$ & $\begin{array}{l}\text { 2-ethylhexanol (after } \\
\text { filtration) [mmol] }\end{array}$ \\
\hline RuCo@C-3 & $1.1 \mathrm{wt} \%$ & $0.126: 1$ & $1.04 \cdot 10^{-3}$ & 8.69 & 12.83 \\
\hline $\mathrm{RuCo} @ \mathrm{Al}_{2} \mathrm{O}_{3}-2$ & $1.8 w t \%$ & $0.132: 1$ & $1.04 \cdot 10^{-3}$ & 9.11 & 14.33 \\
\hline RuCo@N-doped-C & $0.3 w t \%$ & $0.022: 1$ & $1.04 \cdot 10^{-3}$ & 9.27 & 12.95 \\
\hline 1 & $0.3 w t \%$ & $0.014: 1$ & $2.75 \cdot 10^{-4}$ & 17.69 & 17.48 \\
\hline
\end{tabular}

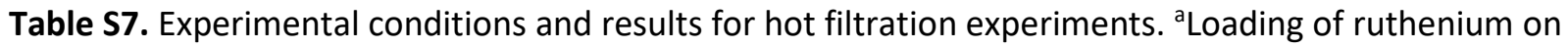
the support material bamount of ruthenium present in the reaction mixture 
Similar to butanol upgrading reactions performed in the presence of $5 \mathrm{~mol} \% \mathrm{NaOBu}$ (see Figure 4), no leaching of catalytically active species is observed with butanol upgrading reactions catalyzed by 1 in the presence of $2.5 \mathrm{~mol} \% \mathrm{NaOBu}$ (Figure S23).

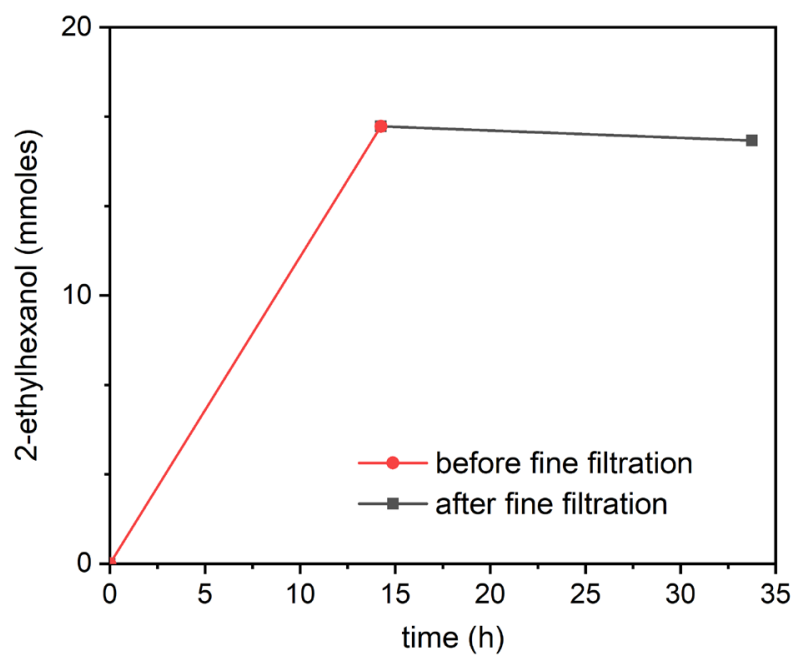

Figure S23. Hot filtration of butanol upgrading reaction with $\mathbf{1}\left(\mathrm{Ru}(\mathrm{COD}) \mathrm{Cl}_{2}\right.$ catalyst precursor, $\mathrm{Ru}: \mathrm{Co}=$ $0.014: 1$ ) using $2.5 \% \mathrm{NaOBu}$ base additive. The reaction mixture was filtered three times, using a filter that does not permit the passage of particles $>200 \mathrm{~nm}$ in size, after $14.5 \mathrm{~h}$ reaction time before the filtrate was heated again for 19.5 hours.

Leaching of catalytically active species was observed even with only $2.5 \mathrm{~mol} \%$ co-catalyst when the $\mathrm{Ru}$ :Co ratio in the precatalyst was as high as $0.049: 1$ (Figure S24). Ensuring that the Ru:Co ratio is kept around $0.02: 1$ is therefore crucial to ensuring that 1 functions as a heterogeneous catalyst.

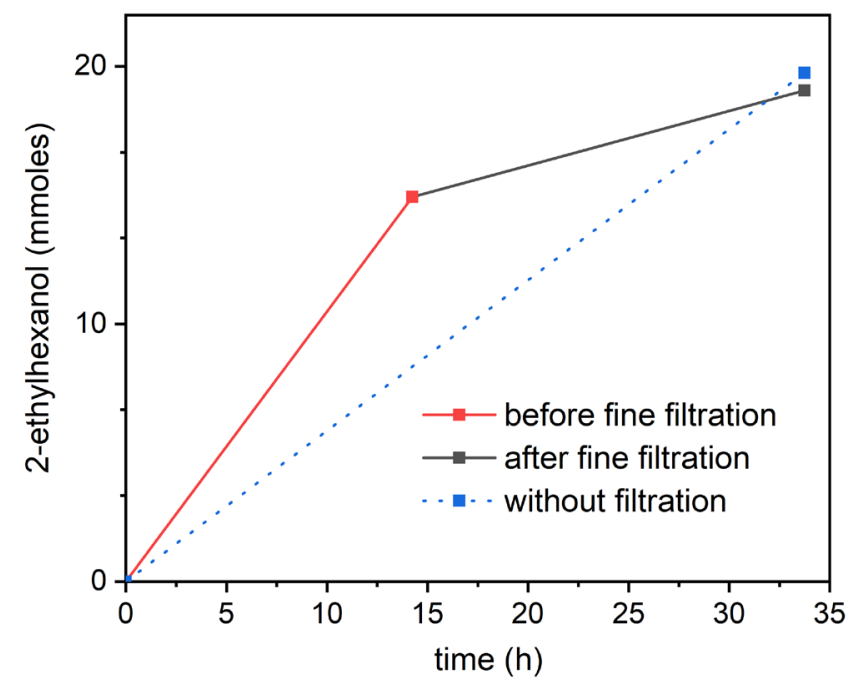


Figure S24. Hot filtration of butanol upgrading reaction with $\mathbf{1}\left(\mathrm{Ru}(\mathrm{COD}) \mathrm{Cl}_{2}\right.$ catalyst precursor, $\mathrm{Ru}: \mathrm{Co}=$ $0.049: 1$ ) using $2.5 \% \mathrm{NaOBu}$ base additive. The reaction mixture was filtered three times, using a filter that does not permit the passage of particles $>200 \mathrm{~nm}$ in size, after $14.5 \mathrm{~h}$ reaction time before the filtrate was heated again for 19.5 hours.

Leaching of catalytically active species from 1 during butanol upgrading reactions was observed when a high loading of NaOBu co-catalyst was employed (Figure S25).

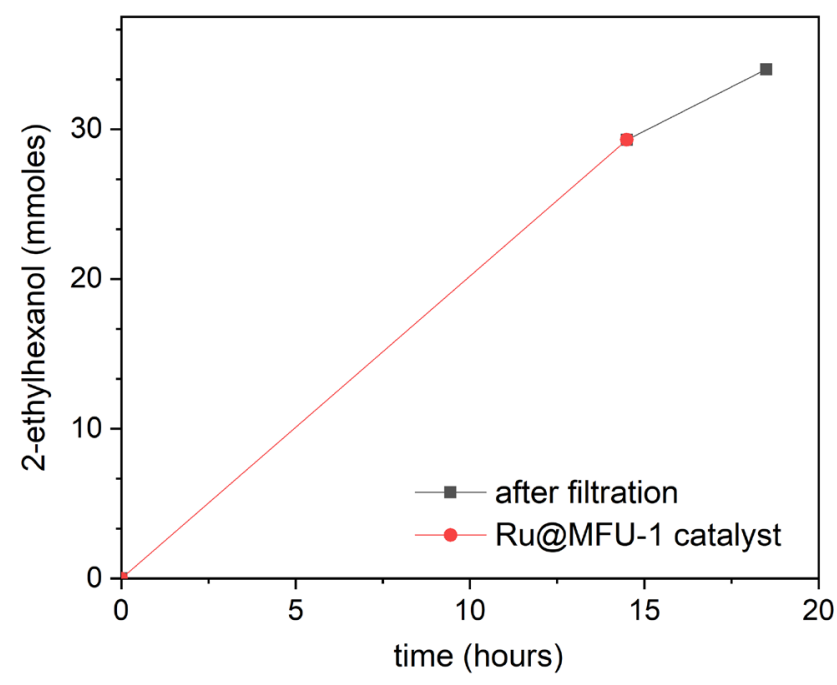

Figure S25. Hot filtration of butanol upgrading reaction with $\mathbf{1}\left(\mathrm{Ru}(\mathrm{COD}) \mathrm{Cl}_{2}\right.$ catalyst precursor, $\mathrm{Ru}: \mathrm{Co}=$ 0.014: 1) using $10 \% \mathrm{NaOBu}$ base additive. The reaction mixture was filtered three times, using a filter that does not permit the passage of particles $>200 \mathrm{~nm}$ in size, after $14.5 \mathrm{~h}$ reaction time before the filtrate was heated again for 4 hours.

\begin{tabular}{l|ccc} 
Element & Reaction mixture & Filtrate of reaction mixture & $\begin{array}{c}\text { Percentage of metal leached } \\
\text { from MOF support }\end{array}$ \\
\hline Cobalt & $9.63 \cdot 10^{4} \mathrm{ppb}$ & $1.01 \cdot 10^{3} \mathrm{ppb}$ & 1.1 \\
ruthenium & $5.24 \cdot 10^{3} \mathrm{ppb}$ & $277 \mathrm{ppb}$ & 5.3
\end{tabular}

Table S8. ICP-MS analysis of a butanol upgrading reaction in the presence of $10 \mathrm{~mol} \% \mathrm{NaOBu}$ promoter mixture catalyzed by 1 filtered after 14.5 hours at $170{ }^{\circ} \mathrm{C}$.

\section{Side Product Profile}

\section{Cannizzaro/Tischchenko reaction}

The only solid side product detected in butanol upgrading reactions was sodium butanoate, the sodium salt of the carboxylic acid derived from the starting alcohol via oxidation (Figure S26). Cannizzaro and Tishchenko reaction are known side reactions in Guerbet processes, which furnish sodium carboxylate 
salts either directly (Cannizzaro) or via in-situ ester hydrolysis (Tishchenko). Sodium acetate, for example, is a commonly observed side product of ethanol upgrading via a Guerbet reaction. ${ }^{9-10}$

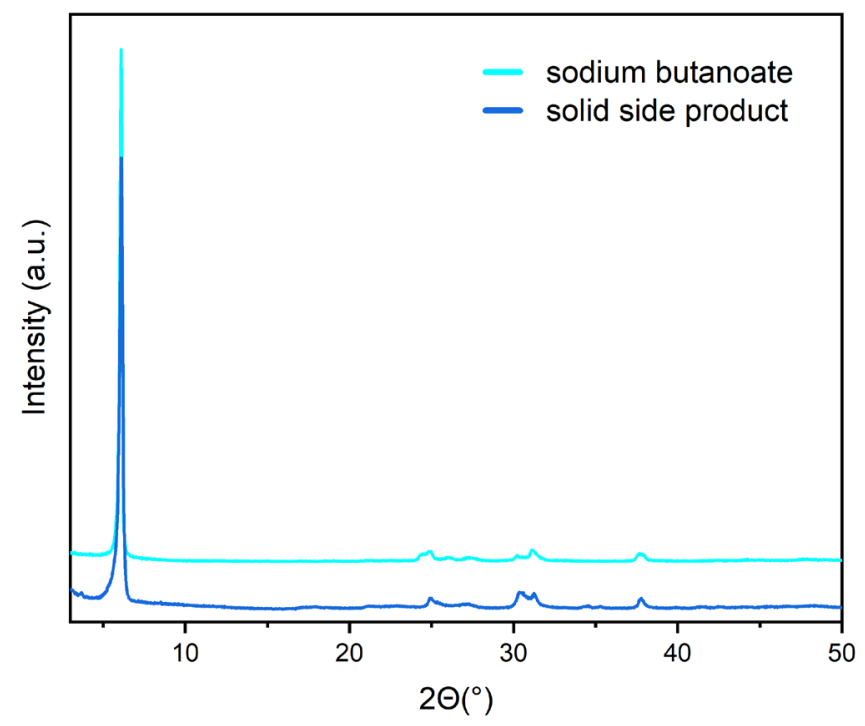

Figure S26. Comparison of the powder X-ray diffraction pattern of the white solid recovered from the Guerbet reaction of 1-butanol catalyzed by 1 with an experimental diffraction pattern of sodium butanoate.

Formation of sodium carboxylates via a Cannizzaro or Tishchenko reaction requires that $\mathrm{H}_{2}$ is formed in equimolar amounts to the carboxylate salt. Cooling the reactor at the end of a butanol upgrading reaction in a cold bath containing ice and $\mathrm{NaCl}$, and bubbling the gases present in the headspace of the reactor through a solution of toluene- $\mathrm{d}_{8}$ allowed detection of $\mathrm{H}_{2}$ by ${ }^{1} \mathrm{H}$ NMR (Figure S27). No other volatile side products commonly observed in Guerbet reactions catalyzed by heterogeneous catalysts such as olefins, $\mathrm{CO}$ or $\mathrm{CH}_{4}$ could be detected by ${ }^{1} \mathrm{H}$ NMR, ${ }^{13} \mathrm{C}$ NMR or GC-MS analysis.

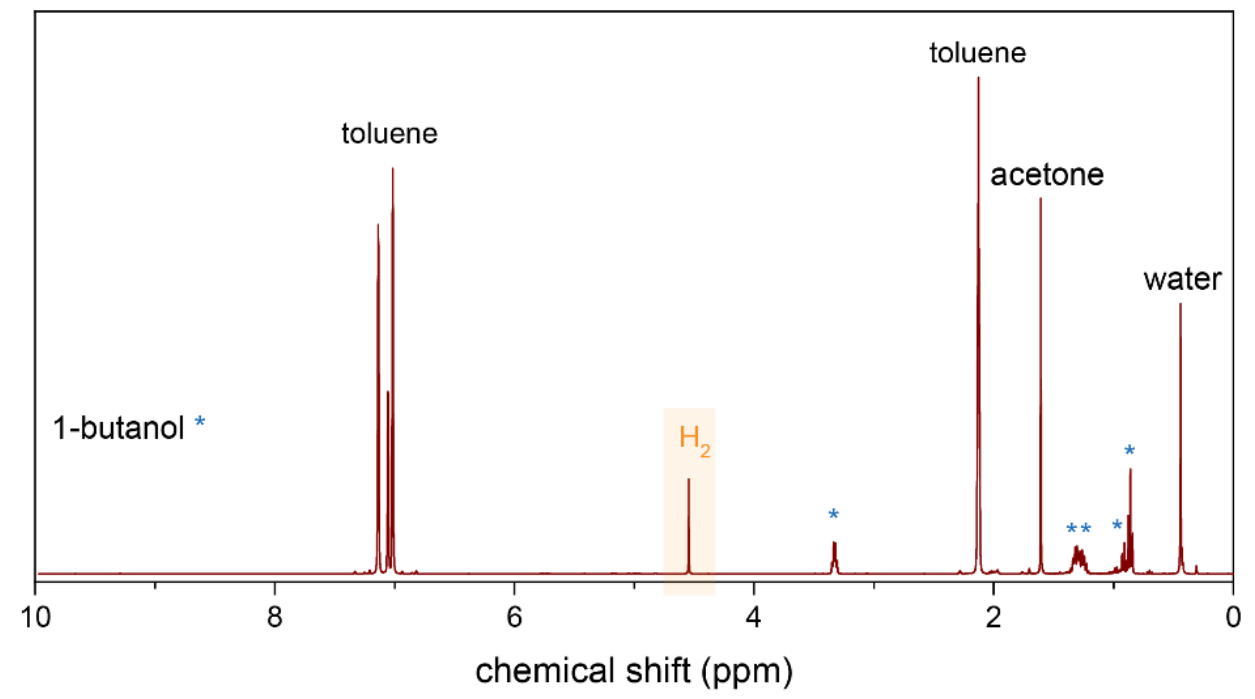


Figure S27. ${ }^{1} \mathrm{H}$ NMR of the gas mixture in the headspace of butanol upgrading reaction dissolved in toluene- $d_{8}$ (residual acetone is present because the NMR tube was cleaned using acetone prior to use).

\section{Unsaturated Guerbet Alcohol Formation}

The only products detected in the liquid phase in addition to the desired Guerbet alcohol were unsaturated derivatives of 2-ethylhexanol (Figure S28 and S29). We assume that these were formed through base catalyzed isomerization of the $\alpha, \beta$-unsaturated aldehyde to yield products not amenable to conjugate reduction. Additionally, unsaturated Guerbet alcohols can be formed if the $\alpha, \beta$-unsaturated aldehyde undergoes direct aldehyde reduction rather than conjugate reduction. Three distinct unsaturated derivatives of 2-ethylhexanol were detected in butanol upgrading reactions. The amount of side product formed was determined using the assumption that the relative response of the GC-MS FID detector of the unsaturated alcohol compared to the $\mathrm{m}$-xylene standard was the same as that of 2ethylhexanol compared to the m-xylene standard.

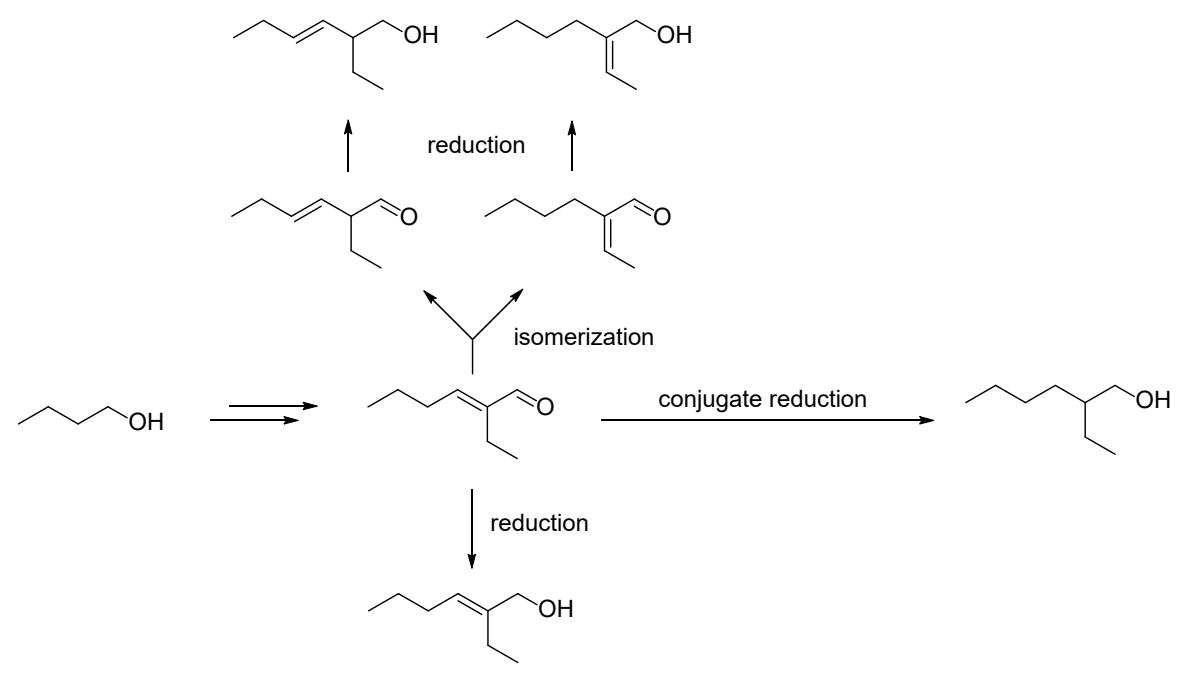

Figure S28. Proposed mechanism of formation of unsaturated $C_{8}$ alcohols in butanol upgrading reactions.

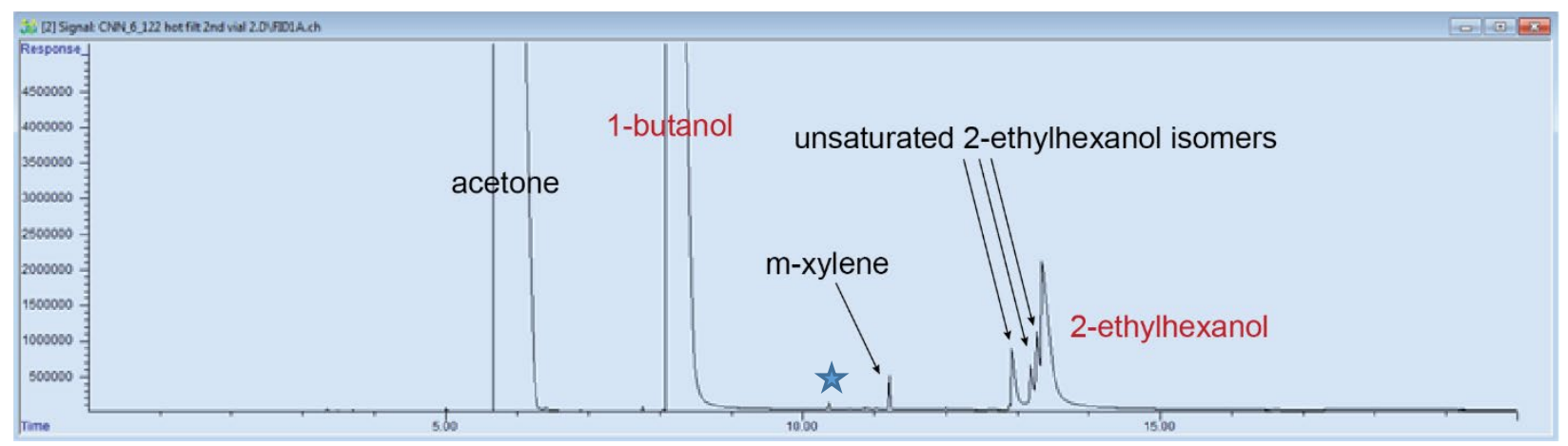

Figure S29. GC-MS analysis, using FID detection, of the crude reaction mixture of a butanol upgrading reaction catalyzed by $\mathrm{RuCo} @ \mathrm{Al}_{2} \mathrm{O}_{3}$ clearly shows the formation of unsaturated $\mathrm{C}_{8}$ alcohols alongside 2ethylhexanol. The peak marked with a blue star corresponds to the aldol condensation product of acetone formed during reaction work-up. 
For butanol upgrading reactions conducted using $\mathrm{LiOH}$ or $\mathrm{K}_{3} \mathrm{PO}_{4}$ as the base promotor, small amounts of 2-ethylhexanal and 2-ethyl-2-hexenal were also observed. Using $\mathrm{NaOBu}$ as the base promoter, however, incomplete carbonyl reduction following aldol condensation was never observed.

\section{Catalyst Recovery and Re-use}

The catalyst was recovered from the reaction mixture along with any sodium carboxylate formed by filtration over a frit. The solid thus collected was dried and weighed to determine the amount of side product formed, before water was added to dissolve sodium butanoate. The water-insoluble catalyst particles were then collected and washed with acetone either by filtration using a fine frit (Table 1, entry 8 ) or by centrifugation (Table 1, entry 2). A fraction of the catalyst was lost during the initial filtration step used to collect both sodium carboxylate and the catalyst due to the small size of some catalyst particles. When determining the extent of leaching observed with different catalyst supports, we subjected all reaction mixture to filtration using $>200 \mathrm{~nm}$ cut-off filters subsequent to filtration using a frit (to remove sodium carboxylate and the majority of the solid catalyst). This step was necessary to ensure that no further catalytic activity was observed in butanol upgrading reactions catalyzed by 1 , and a black color was visible in the $>200 \mathrm{~nm}$ cut-off filter after use. We conclude that some of the catalyst particles formed in situ from Ru@MOF are very small, and recovery of all catalyst particles for re-use is currently not operationally practical. Further work is needed to better control the particle size of the active catalyst formed in situ to ensure facile and efficient catalyst reuse.

The recovered fraction of the catalyst gives rise to $60 \%$ of the activity of pristine catalyst, which may be due either to the loss of small catalyst particles, or to partial de-activation of the catalyst surface during initial use. 
TEM, STEM and EDS Mapping of Recovered 1
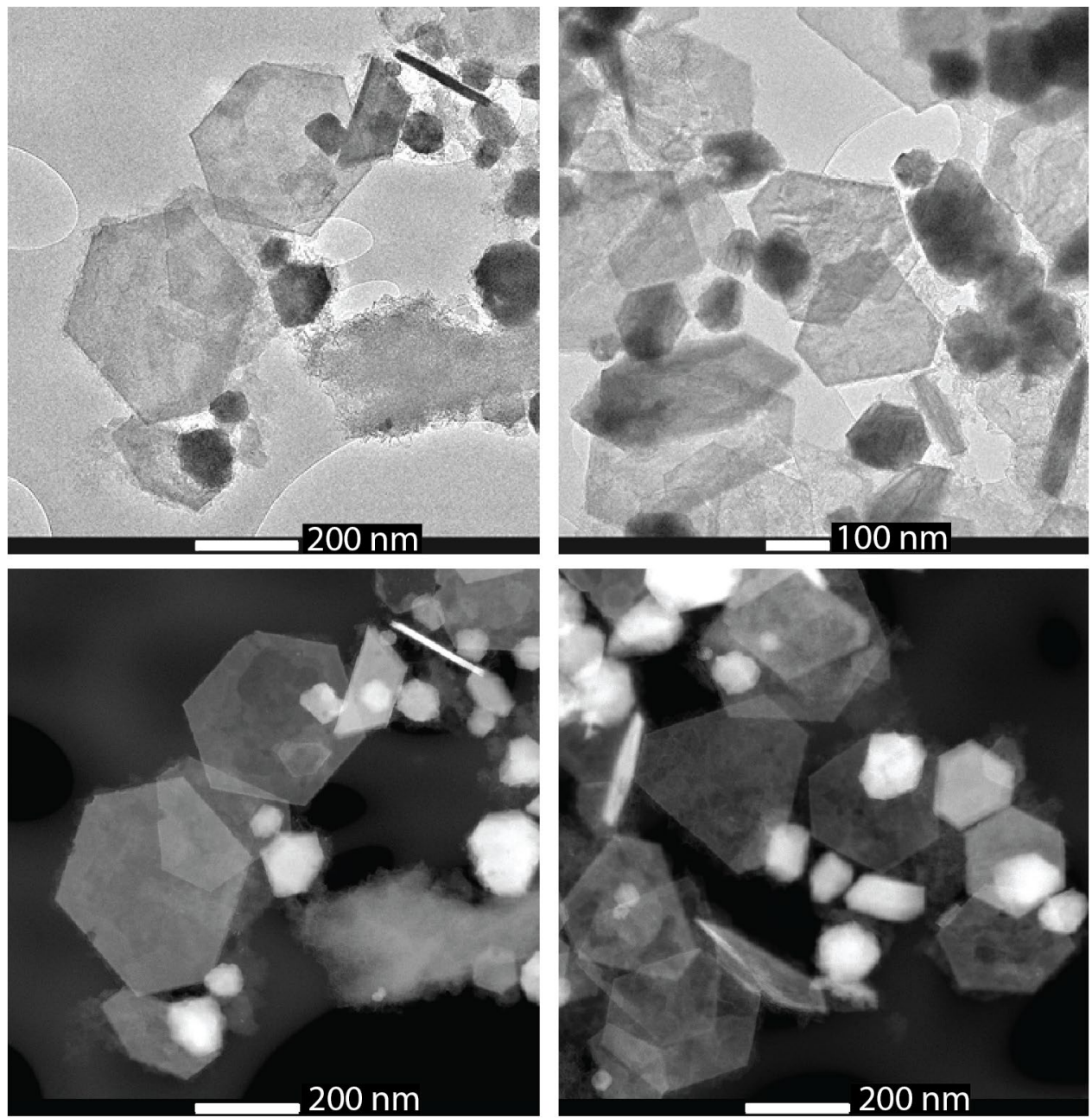

Figure S30. TEM and STEM images of 1 after use as a catalyst in a butanol upgrading reaction with 5\% $\mathrm{NaOBu}$. 

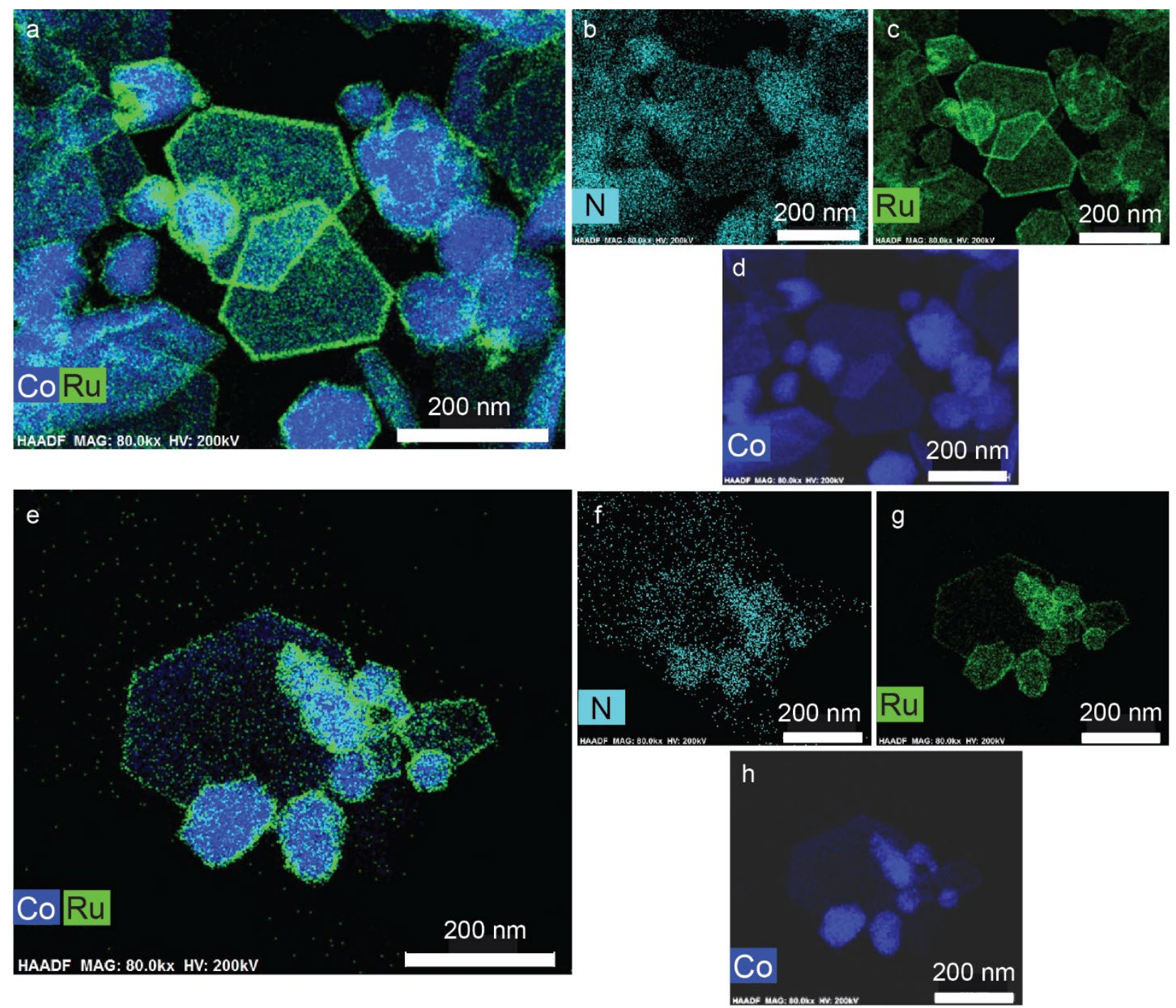

Figure S31. EDS mapping of 1 after use as a catalyst in butanol upgrading reaction with $5 \% \mathrm{NaOBu}$.

\section{Ruthenium Enrichment on the Surface of CoOx nanoparticles}

The average Ru:Co ratio for nanoplates determined by EDS was 0.069:1 $(n=4)$. This constitutes an enrichment of ruthenium in the nanoplates compared to the Ru@MFU-1 precatalyst used to generate this sample of recovered 1 from Ru:Co $=0.049: 1$ to $\mathrm{Ru}: \mathrm{Co}=0.069: 1$. The central area of the round particles, on the other hand, was found to have a low ruthenium content, although ruthenium is clearly visible on the edges of the particle by EDS mapping (Figures S31 and S32).

Comparison with RuCo@C, however, reveals that the surface of the RuCo nanoparticles on carbon support material are also enriched in ruthenium: While the bulk composition a RuCo@C sample with a low loading of metals was determined by ICP-MS to be Ru:Co $=0.13: 1$ (Table S9, entry 2), the surface composition was found to be Ru:Co $=0.23: 1$ (determined by XPS) and Ru:Co $=0.22: 1$ (determined by EDS). 
The enhanced activity of MOF-derived RuCo can thus not be (solely) due to ruthenium being enriched on the surface of RuCo particles, because a similar effect would be expected for RuCo supported on carbon.

To ensure that the lower Ru:Co ratio in the MOF sample is not responsible for its enhanced activity, we prepared a RuCo@C sample with Ru:Co=0.013:1 (RuCo@C-1 and RuCo@C-2), a ratio in line with some of the most active MOF-derived catalysts studied. Interestingly, no surface enrichment of ruthenium could be detected for RuCo@C-1 (Table S9, entry 3). Furthermore, the catalytic activity of RuCo@C-1 and RuCo@C-2 (Ru:Co=0.013:1) was found to be substantially lower than that of RuCo@C-3 (Ru:Co= $0.13: 1$ or Ru:Co $=0.12: 1$ ) (see Table S9).

We speculate, therefore, that the enhanced catalytic activity of MOF-derived RuCo may be due not only to the enrichment of ruthenium on the surface of $\mathrm{CoO}_{x}$ particles, but to their placement on high-energy surface sites, such as along the edges of very thin $\mathrm{CoO}_{x}$ nanoplates (Figures S31-S32).
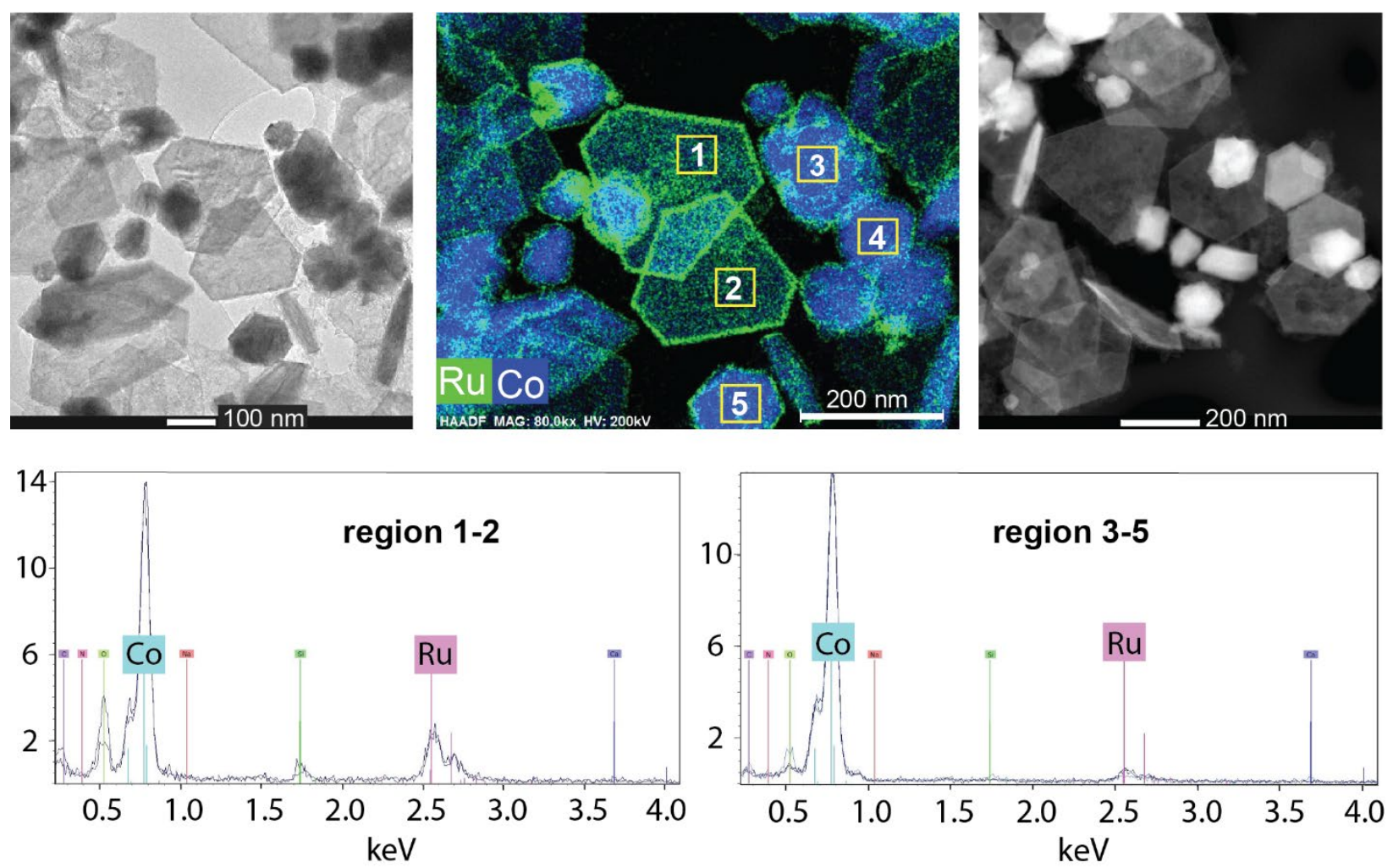

Figure S32. Region-specific EDS spectra of 1 recovered from butanol upgrading reaction.

\begin{tabular}{|c|c|c|c|c|c|c|}
\hline Entry & Catalyst & Ru : Co (ICP-MS) & $\begin{array}{c}\text { Ru wt\% (ICP- } \\
\text { MS) }\end{array}$ & $\begin{array}{c}\text { Surface } \\
\text { Ru: Co (XPS) }\end{array}$ & $\begin{array}{c}\text { Surface } \\
\text { Ru wt\% (XPS) }\end{array}$ & $\begin{array}{c}\text { Surface } \\
\text { Ru : Co (EDS) }\end{array}$ \\
\hline 1 & RuCo@C-4 & $0.116: 1$ & 3.4 & $0.19: 1$ & 6.4 & $0.15: 1$ \\
\hline 2 & RuCo@C-3 & $0.127: 1$ & 1.1 & $0.23: 1$ & 2.7 & $0.22: 1$ \\
\hline 3 & RuCo@C-1 & $0.011: 1$ & 0.7 & $0.014: 1$ & 0.6 & Ru n.d. \\
\hline 4 & $\mathrm{RuCo} @ \mathrm{Al}_{2} \mathrm{O}_{3}$ & $0.132: 1$ & 1.8 & n.d. & n.d. & - \\
\hline
\end{tabular}


Table S9. Ruthenium loading and ruthenium to cobalt ratio as determined by different experimental methods ( .d. $=$ not detected).

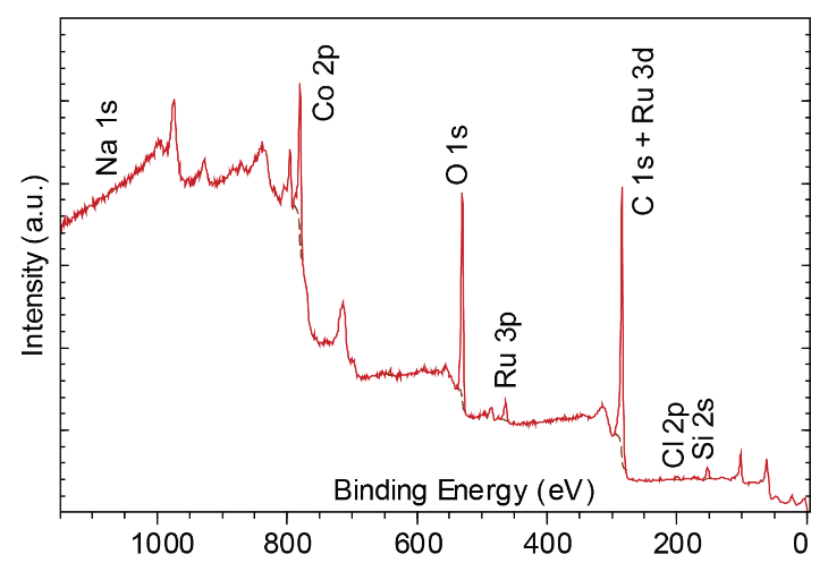

Figure S33. XPS spectrum of RuCo@C with a high loading of metals on the support (RuCo@C-4).

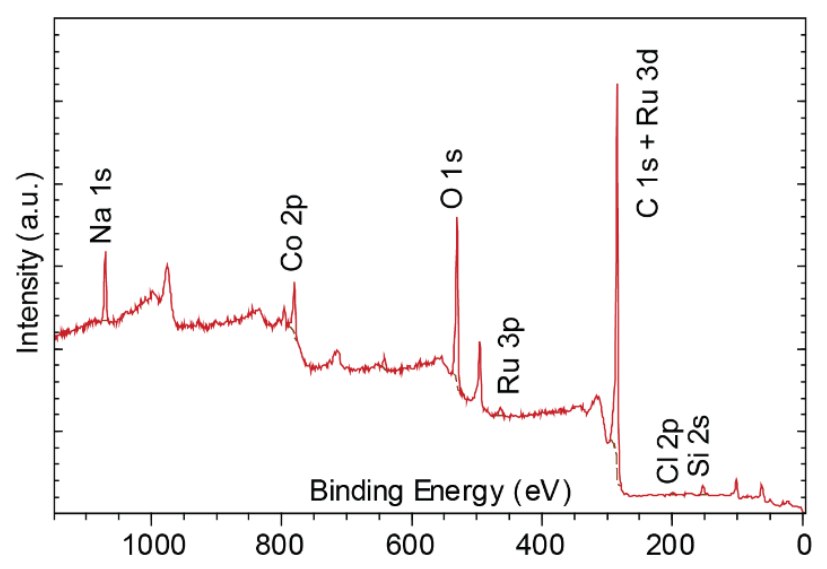

Figure S34. XPS spectrum of RuCo@C with a low loading of metals on the support (RuCo@C-3). 


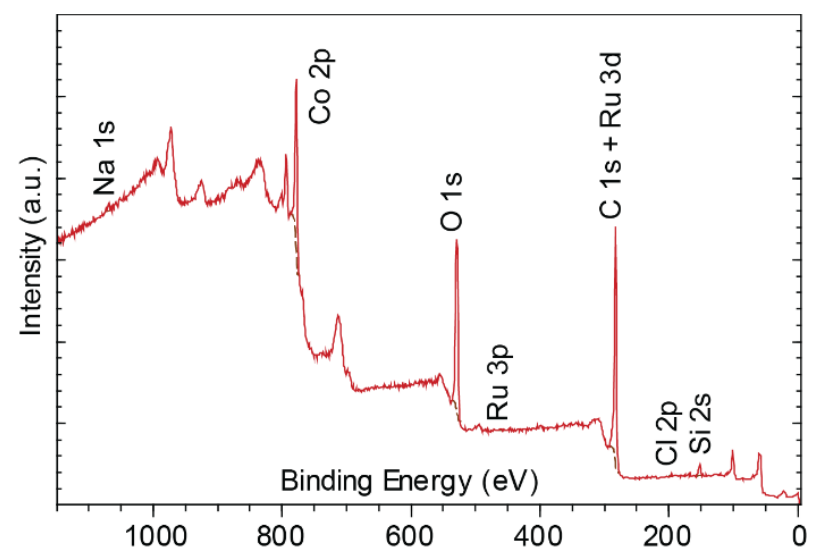

Figure S35. XPS spectrum of RuCo@C with a low Ru to Co ratio (RuCo@C-1).

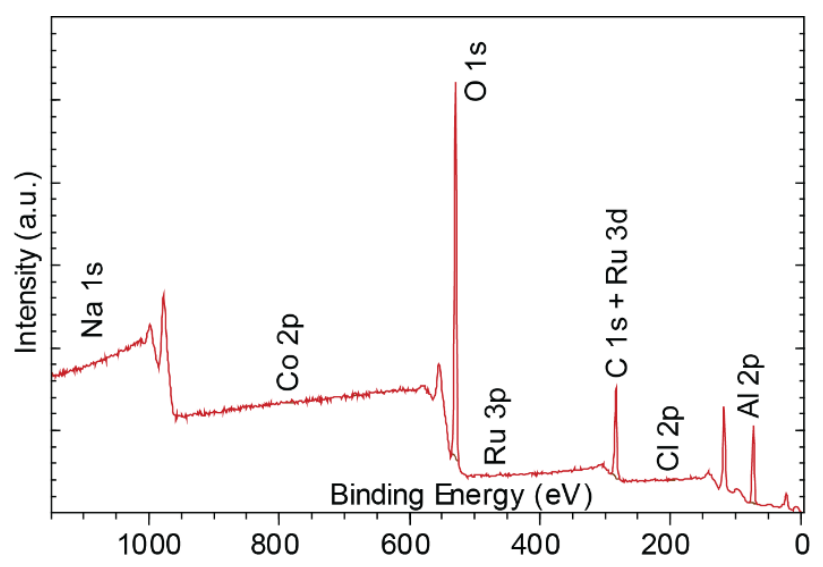

Figure S36. XPS spectrum of RuCo@ $\mathrm{Al}_{2} \mathrm{O}_{3}$ with a high loading of metals on the support ( $\left.\mathrm{RuCo} @ \mathrm{Al}_{2} \mathrm{O}_{3}-2\right)$. 


\section{Effect of Nanoparticle Size and Composition on Catalyst Activity}

The effect of the nanoparticle size and composition was evaluated via 1-butanol upgrading experiments using an amount of catalyst corresponding to $5.0 \cdot 10^{-4} \mathrm{mmol} \mathrm{Ru}$ at $170^{\circ} \mathrm{C}$ for $19 \mathrm{~h}$ (see Table S10). Lower catalytic activity was observed using RuCo@C-2 versus RuCo@C-1, indicating that the smaller RuCo nanoparticles present in RuCo@C-1 led to higher catalytic activity. A significantly higher catalytic activity was observed using RuCo@C-3, which contained RuCo nanoparticles with a much higher Ru : Co ratio, than with RuCo@C-1 or RuCo@C-2, which contained RuCo nanoparticles with a lower Ru : Co ratio (Table S10).

\begin{tabular}{|c|c|c|c|c|c|c|}
\hline & $\mathrm{Ru}: \mathrm{Co}$ & loading [wt\%] & $\mathrm{Ru}[\mathrm{mmol}]$ & $\operatorname{TON}\left[\mathrm{Ru}^{-1}\right]$ & $\operatorname{TOF}\left[\mathrm{Ru}^{-1} \mathrm{~h}^{-1}\right]$ & Sel. (Guerbet) \\
\hline RuCo@C-1 & $0.011: 1$ & 0.7 & $5.0 \cdot 10^{-4}$ & 68710 & 3616 & 0.73 \\
\hline RuCo@C-2 & $0.011: 1$ & 0.7 & $5.0 \cdot 10^{-4}$ & 58317 & 3069 & 0.71 \\
\hline RuCo@C-3 & $0.127: 1$ & 1.1 & $5.0 \cdot 10^{-4}$ & 85370 & 4493 & 0.75 \\
\hline
\end{tabular}

Table S10. Comparative activity of RuCo@C batches in 1-butanol upgrading reactions at $170^{\circ} \mathrm{C}$.

\section{Replacement of $\mathrm{NaOBu}$ with $\mathrm{K}_{2} \mathrm{CO}_{3}$}

Use of $\mathrm{K}_{2} \mathrm{CO}_{3}$ as a base promoter in butanol upgrading reactions leads to the recovery of catalyst material that still has its original blue color (instead of the black color observed when $\mathrm{NaOBu}, \mathrm{NaOH}$ or $\mathrm{K}_{3} \mathrm{PO}_{4}$ was employed). PXRD analysis indicated that the MOF support retained crystallinity (Figure S37). No sodium butyrate or desired Guerbet alcohol could be detected in the reaction mixture, but saturated and unsaturated $\mathrm{C}_{8}$ alcohols were detected in small quantities.

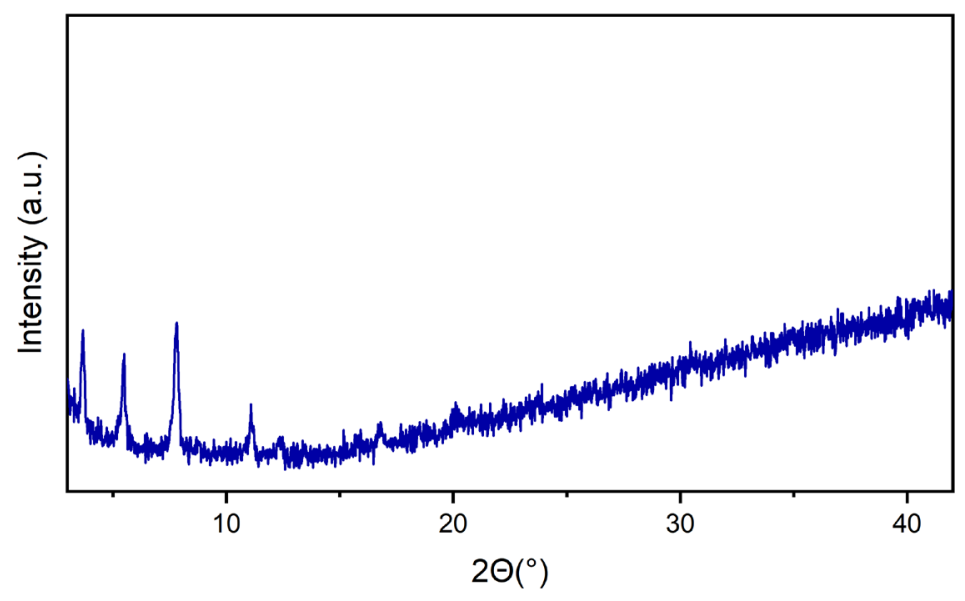

Figure S37. Powder $\mathrm{X}$-ray diffraction pattern of 1 recovered from butanol upgrading reaction conducted in the presence of $\mathrm{K}_{2} \mathrm{CO}_{3}(5 \mathrm{~mol} \%)$ as a base promoter.

\section{Experimental Procedure and Detailed Results for Experiments in Figure 6}

\section{1-butanol upgrading with $\mathrm{Ru}(\mathrm{COD}) \mathrm{Cl}_{2}$}

Amount of $[\mathrm{Ru}]$ used per experiment $=0.00027 \mathrm{mmol}$; Ru:Co ratio of 1 : entry $1=0.0142: 1.000$, entry $2,3=0.0043: 1.000$ 


\begin{tabular}{|c|c|c|c|c|c|c|c|c|c|c|}
\hline $\begin{array}{l}\text { Ru } \\
\text { ligand }\end{array}$ & $\begin{array}{l}\mathrm{NaOBu} \\
\text { [mol\%] }\end{array}$ & $\begin{array}{c}\text { Time } \\
{[\mathrm{h}]}\end{array}$ & $\begin{array}{c}\text { TON } \\
{\left[R u^{-1}\right]}\end{array}$ & $\begin{array}{c}\text { TOF } \\
{\left[\mathrm{Ru}^{-1} \mathbf{h}^{-1}\right]}\end{array}$ & Conv. & $\begin{array}{c}\text { Mass } \\
\text { balance }\end{array}$ & $\begin{array}{c}\text { Sel. } \\
\text { (Guerbet) }\end{array}$ & $\begin{array}{l}\text { Sel. } \\
\text { (unsat.) }\end{array}$ & $\begin{array}{c}\text { Sel } \\
\text { (Carbox.) }\end{array}$ & $\begin{array}{c}\text { Product } \\
{[\mu \mathrm{L}]}\end{array}$ \\
\hline COD & $10 \%$ & 14 & 305642 & 21832 & 0.39 & 0.99 & 0.76 & 0.05 & 0.19 & 4959 \\
\hline COD & $5 \%$ & 15.5 & 237713 & 15336 & 0.27 & 1.04 & 0.84 & 0.06 & 0.11 & 4283 \\
\hline COD & $2.50 \%$ & 18 & 193652 & 10758 & 0.28 & 0.99 & 0.86 & 0.07 & 0.06 & 3589 \\
\hline
\end{tabular}

1-butanol upgrading with $\mathrm{Ru}(\mathrm{nbd}) \mathrm{Cl}_{2}$

Amount of $[\mathrm{Ru}]$ used per experiment $=0.00028 \mathrm{mmol}$; Ru:Co ratio of 1 : entry $1=0.0104: 1.000$, entry 2 , $3=0.0142: 1.000$

\begin{tabular}{|c|c|c|c|c|c|c|c|c|c|c|}
\hline $\begin{array}{l}\text { Ru } \\
\text { ligand }\end{array}$ & $\begin{array}{l}\mathrm{NaOBu} \\
\text { [mol\%] }\end{array}$ & $\begin{array}{c}\text { Time } \\
{[\mathrm{h}]}\end{array}$ & $\begin{array}{c}\text { TON } \\
{\left[\mathrm{Ru}^{-1}\right]}\end{array}$ & $\begin{array}{c}\text { TOF } \\
{\left[R u^{-1} h^{-1}\right]}\end{array}$ & Conv. & $\begin{array}{c}\text { Mass } \\
\text { balance }\end{array}$ & $\begin{array}{c}\text { Sel. } \\
\text { (Guerbet) }\end{array}$ & $\begin{array}{l}\text { Sel. } \\
\text { (unsat.) }\end{array}$ & $\begin{array}{c}\text { Sel } \\
\text { (Carbox.) }\end{array}$ & $\begin{array}{l}\text { Product } \\
{[\mu \mathrm{L}]}\end{array}$ \\
\hline$n b d$ & $10 \%$ & 14 & 243822 & 17416 & 0.35 & 0.98 & 0.75 & 0.05 & 0.20 & 3991 \\
\hline$n b d$ & $5 \%$ & 15.5 & 187891 & 12122 & 0.25 & 1.00 & 0.83 & 0.09 & 0.08 & 3405 \\
\hline$n b d$ & $2.5 \%$ & 18 & 190538 & 10585 & 0.26 & 1.00 & 0.85 & 0.11 & 0.04 & 3542 \\
\hline
\end{tabular}

\section{Butanol Upgrading with Base Promoters Other than NaOBu}

For butanol upgrading reactions performed in the presence of either $\mathrm{LiOH}$ or $\mathrm{K}_{3} \mathrm{PO}_{4}$, the amount of solid recovered from the reaction mixture was equal (within experimental error of $\pm 4 \%$ ) to the amount of base and catalyst added at the start of the reaction. Analysis of the solid recovered from butanol upgrading reactions using $\mathrm{K}_{3} \mathrm{PO}_{4}$ (Figure S39) did not reveal the presence of either potassium butanoate (from the Cannizzaro side reaction).

LiOH base co-catalyst

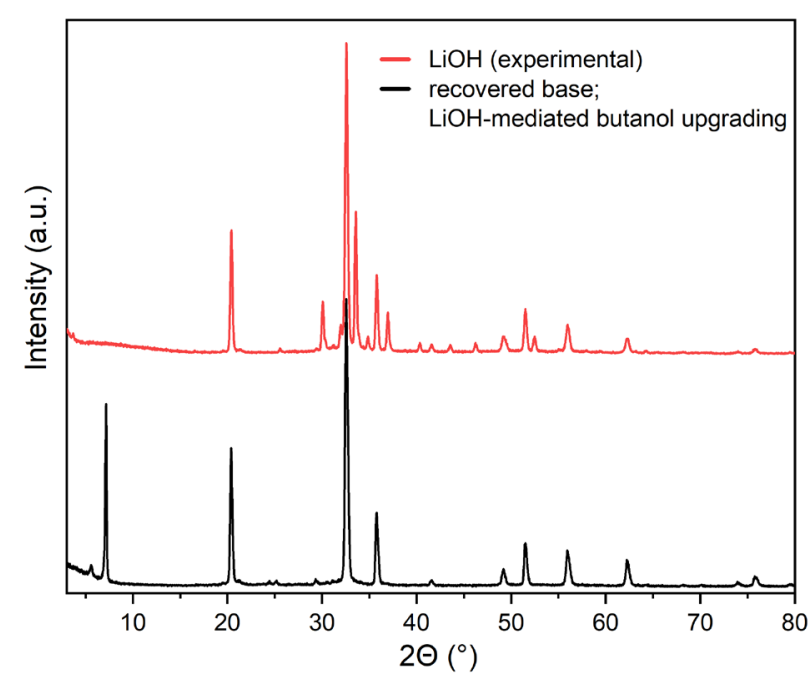

Figure S38. Comparison of powder X-ray diffraction pattern of solid recovered from butanol upgrading reaction catalyzed by $\mathbf{1}$ and $\mathrm{LiOH}$ and a fresh sample of $\mathrm{LiOH}$. 


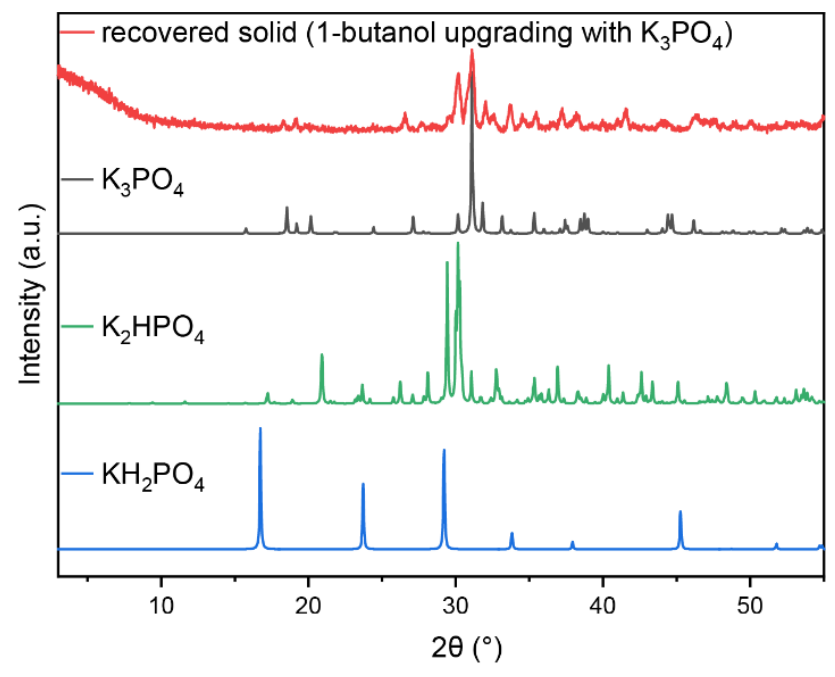

Figure S39. Powder X-ray diffraction pattern of solid recovered from butanol upgrading reaction catalyzed by 1 and $\mathrm{K}_{3} \mathrm{PO}_{4}$ indicates that no potassium butyrate (side product derived from the Cannizzaro reaction of 1-butanol) was formed (compare with Figure S26). ${ }^{11}$ No evidence for the formation of $\mathrm{KH}_{2} \mathrm{PO}_{4}$ was found, but given the significant differences between the recovered solid and the predicted PXRD pattern for $\mathrm{K}_{3} \mathrm{PO}_{4}$, we cannot exclude formation of $\mathrm{K}_{2} \mathrm{HPO}_{4}$.

Catalyst 1 and $\mathrm{K}_{3} \mathrm{PO}_{4}$ (from the experiment described in Table 1, entry 3) were removed from the reaction mixture by filtration over a medium frit. After analysis, the solids were placed back into the Parr pressure vessel, a fresh batch of 1-butanol $(20.0 \mathrm{~mL})$ was added to the reactor. Upgrading of 1-butanol with recovered 1 and $\mathrm{K}_{3} \mathrm{PO}_{4}$, and analysis of the resulting reaction mixture was then conducted analogously to the reaction containing a fresh batch of 1 and $\mathrm{K}_{3} \mathrm{PO}_{4}$ (Table S11).

\begin{tabular}{|c|c|c|c|c|c|c|c|c|c|}
\hline entry & $\begin{array}{c}\text { Time } \\
{[\mathrm{h}]}\end{array}$ & $\begin{array}{c}\text { TON } \\
{\left[R u^{-1}\right]}\end{array}$ & $\begin{array}{c}\text { TOF } \\
{\left[R u^{-1} h^{-1}\right]}\end{array}$ & Conv. & $\begin{array}{c}\text { Mass } \\
\text { balance }\end{array}$ & $\begin{array}{c}\text { Sel. } \\
\text { (Guerbet) }\end{array}$ & $\begin{array}{l}\text { Sel. } \\
\text { (unsat.) }\end{array}$ & $\begin{array}{c}\text { Sel } \\
\text { (aldeh.) }\end{array}$ & $\begin{array}{l}\text { Product } \\
{[\mu \mathrm{L}]}\end{array}$ \\
\hline $\begin{array}{c}\text { Fresh }(1+ \\
\left.\mathrm{K}_{3} \mathrm{PO}_{4}\right)\end{array}$ & 15.5 & 1051859 & 67862 & 0.20 & 0.96 & 0.80 & 0.16 & 0.04 & 2202 \\
\hline $\begin{array}{c}\text { Re-used }(1+ \\
\left.\mathrm{K}_{3} \mathrm{PO}_{4}\right)\end{array}$ & 15.5 & 469783 & 30309 & 0.13 & 0.95 & 0.52 & 0.37 & 0.11 & 643 \\
\hline
\end{tabular}

Table S11. Comparison of the performance of fresh and re-used catalytic system ( 1 and $\left.\mathrm{K}_{3} \mathrm{PO}_{4}\right)$ in 1butanol upgrading. 


\section{References}

1. Abel, E. W.; Bennett, M. A.; Wilkinson, G., 646. Norbornadiene-metal complexes and some related compounds. J. Chem. Soc. 1959, (0), 3178-3182.

2. Tonigold, M.; Lu, Y.; Bredenkötter, B.; Rieger, B.; Bahnmüller, S.; Hitzbleck, J.; Langstein, G.; Volkmer, D., Heterogeneous Catalytic Oxidation by MFU-1: A Cobalt(II)-Containing Metal-Organic Framework. Angew. Chem. Int. Ed. 2009, 48 (41), 7546-7550.

3. Tonigold, M.; Lu, Y.; Mavrandonakis, A.; Puls, A.; Staudt, R.; Mollmer, J.; Sauer, J.; Volkmer, D., Pyrazolate-based cobalt(II)-containing metal-organic frameworks in heterogeneous catalytic oxidation reactions: elucidating the role of entatic states for biomimetic oxidation processes. Chem. Eur. J. 2011, 17 (31), 8671-95.

4. Liu, D.; Chen, X.; Xu, G.; Guan, J.; Cao, Q.; Dong, B.; Qi, Y.; Li, C.; Mu, X., Iridium nanoparticles supported on hierarchical porous $\mathrm{N}$-doped carbon: an efficient water-tolerant catalyst for bio-alcohol condensation in water. Sci. Rep. 2016, 6, 21365.

5. Wang, F.; Wang, Y.; Zhang, Y.; Luo, Y.; Zhu, H., Highly dispersed RuCo bimetallic nanoparticles supported on carbon black: enhanced catalytic activity for hydrogen generation from $\mathrm{NaBH} 4$ methanolysis. J. Mater. Sci. 2018, 53.

6. Rachiero, G. P.; Demirci, U. B.; Miele, P., Bimetallic RuCo and RuCu catalysts supported on $\gamma^{-}$ Al2O3. A comparative study of their activity in hydrolysis of ammonia-borane. Int. J. Hydrogen Energy 2011, 36 (12), 7051-7065.

7. Ravenelle, R. M.; Copeland, J. R.; Kim, W.-G.; Crittenden, J. C.; Sievers, C., Structural Changes of Y-Al2O3-Supported Catalysts in Hot Liquid Water. ACS Catal. 2011, 1 (5), 552-561.

8. Koichumanova, K. In situ infrared spectroscopy under hydrothermal conditions: application for aqueous phase reforming. PhD Thesis, Universiteit Twente, Enschede, 2015.

9. $\quad$ Fu, S.; Shao, Z.; Wang, Y.; Liu, Q., Manganese-Catalyzed Upgrading of Ethanol into 1-Butanol. J. Am. Chem. Soc. 2017, 139 (34), 11941-11948.

10. Kulkarni, N. V.; Brennessel, W. W.; Jones, W. D., Catalytic Upgrading of Ethanol to n-Butanol via Manganese-Mediated Guerbet Reaction. ACS Catal. 2018, 8 (2), 997-1002.

11. Lomer, T., The unit-cell dimensions of potassium soaps. Acta Cryst. 1952, 5 (1), 11-14. 